\title{
Biogenesis, Membrane Trafficking, Functions, and Next Generation Nanotherapeutics Medicine of Extracellular Vesicles
}

\author{
Sangiliyandi Gurunathan (D)' \\ Min-Hee Kang (D' \\ Muhammad Qasim (iD) ${ }^{2}$ \\ Khalid Khan ${ }^{3}$ \\ Jin-Hoi Kim (iD) \\ 'Department of Stem Cell and \\ Regenerative Biotechnology, Konkuk \\ University, Seoul, 05029, Korea; ${ }^{2}$ Center \\ of Bioengineering and Nanomedicine, \\ Department of Food Science, University \\ of Otago, Dunedin, 9054, New Zealand; \\ ${ }^{3}$ Science and Technology KPK, Peshawar, \\ Pakistan
}

Correspondence: Sangiliyandi Gurunathan; Jin-Hoi Kim

Department of Stem Cell and Regenerative Biotechnology, Konkuk University, Seoul,

05029, Korea

Tel +82 24503687

Fax +822544 4645

Email gsangiliyandi@yahoo.com;

jhkim54I@konkuk.ac.kr

\begin{abstract}
Extracellular vesicles (EVs) are a heterogeneous group of membrane-limited vesicles and multi-signal messengers loaded with biomolecules. Exosomes and ectosomes are two different types of EVs generated by all cell types. Their formation depends on local microdomains assembled in endocytic membranes for exosomes and in the plasma membrane for ectosomes. Further, EV release is a fundamental process required for intercellular communication in both normal physiology and pathological conditions to transmit/exchange bioactive molecules to recipient cells and the extracellular environment. The unique structure and composition of EVs enable them to serve as natural nanocarriers, and their physicochemical properties and biological functions can be used to develop next-generation nano and precision medicine. Knowledge of the cellular processes that govern EVs biology and membrane trafficking is essential for their clinical applications. However, in this rapidly expanding field, much remains unknown regarding EV origin, biogenesis, cargo sorting, and secretion, as well as EV-based theranostic platform generation. Hence, we present a comprehensive overview of the recent advances in biogenesis, membrane trafficking, and functions of EVs, highlighting the impact of nanoparticles and oxidative stress on EVs biogenesis and release and finally emphasizing the role of EVs as nanotherapeutic agents.
\end{abstract}

Keywords: extracellular vesicle, membrane trafficking, vesicle formation, cargo sorting and fusion, nanotherapeutics

\section{Introduction}

Extracellular vesicles (EVs) are derived either from the endosomal compartment or as a result of shedding from the plasma membrane. EVs carry a variety of cargo, including RNAs, proteins, lipids, bioactive enzymes, molecules, molecular information, and DNA, and are released from all types of cells, including prokaryotic and eukaryotic cells ${ }^{1,2}$ The ISEV consensus recommendation on nomenclature is to use "extracellular vesicle" as the "generic term for particles naturally released from the cell that are delimited by a lipid bilayer and cannot replicate" and to modify "EV" based on clear, measurable characteristics. ${ }^{3,4}$ EVs plays vital role in cell to cell communication in normal and pathological conditions, theranostic applications and disease detection. ${ }^{5-11} \mathrm{EV}$ secretion is found in almost all bodily fluids and the secretion of EVs is a process that appears to be conserved throughout evolution. ${ }^{12}$ EVs are classified into different types based on their origin, size, nature, biogenesis, and functions - namely, exosomes, microparticles, microvesicles (MVs), apoptotic bodies, ectosomes, and oncosomes. ${ }^{13}$ The term exosome was initially used to name 
vesicles ranging from 40 to $1000 \mathrm{~nm}$ released by various cultured cells ${ }^{14}$ but was later adopted for vesicles ranging from 30 to $100 \mathrm{~nm}$ in size. ${ }^{15}$ The size and origin of exosomes from endosomes were first confirmed in B lymphocytes and dendritic cells. ${ }^{16,17}$ EVs are released by "donor" cells either through the outward budding of the plasma membrane or inward budding of the endosomal membrane by shedding MVs or ectosomes, ${ }^{18}$ which results in the formation of multivesicular bodies (MVBs); exosomes are then released by fusion of the outer MVB membrane to the plasma membrane. ${ }^{10,19} \mathrm{EV}$ biogenesis is mainly dependent on members of the endosomal sorting complex required for transport (ESCRT) pathway. ${ }^{20}$ Jeppesen et al employed high-resolution density gradient fractionation and direct immunoaffinity capture to precisely characterize the RNA, DNA, and protein constituents of exosomes and other non-vesicle material. ${ }^{21}$

Genetic studies have demonstrated that biogenesis and secretion of EVs are controlled by specific proteins such as GTPases and lipids. The Rab family of small GTPases plays a critical role in intracellular trafficking, and several Rabs play a significant role in EVs release, including Rab27a, Rab27b, Rab35, and Rab11. ${ }^{22-28}$ EVs production and release can be altered or regulated and may be inhibited or stimulated by internal cellular processes or external stimuli. Studies have demonstrated that cancer cells produce greater numbers of EVs than non-transformed healthy cells. ${ }^{29,30}$ Cell stress is a possible factor increasing EVs production through the modulation of intracellular calcium levels in cancer cells. ${ }^{31}$ Cargo selection, packaging, and compartmentalization are inevitable processes regulated at multiple levels. The ESCRT-dependent pathway is involved in the selection and distribution of proteins within exosomes. ${ }^{32} \mathrm{CD} 63$ is involved in sorting EVs cargo, ${ }^{33}$ ADP ribosylation factor 6 (ARF6)- and it directs cargo selection in MVs. ${ }^{34}$ These specific cargo mechanisms suggest that ubiquitin-dependent ESCRT sorting mechanisms. $^{35}$

Recently, EVs have received much interest owing to their unique role in early detection and diagnosis for the improvement of treatment outcomes in cancer. ${ }^{36}$ Accumulating evidence suggests that the cargo molecules carried by EVs originating from cancer cells facilitate the identification of specific biomarkers for diagnosing cancer and predicting therapeutic outcomes. ${ }^{37}$ Nanotechnology provides enormous opportunities to develop novel nanomaterials to revolutionize our ways of living, especially nanomedicine. Exosomes are a subset of EVs and are small membrane vesicles of endocytic origin that function as signalosomes and transmit amounts of bioactive molecules to specific recipient cells for intercellular communication, thus playing critical roles in various diseases. ${ }^{38}$ Exosome nanotechnology plays a major role in understanding the interdependent relationships between exosomes and their underlying biology, chemistry, and pharmacy. The cell-derived hierarchical nanoarchitecture enables exosomes to serve as natural nanocarriers with excellent biocompatibility and bioavailability compared with traditional synthetic nanocarriers. ${ }^{39}$ The combination of exosomes and nanotechnology can facilitate the development of next-generation theranostic nanoplatforms.

Recently, a type of small $(<50 \mathrm{~nm})$, non-membranous nanoparticle, extracellular nanoparticle with no known biological function, termed exomere shows immense interest. ${ }^{40}$ Biological macromolecules such as proteins, nucleic acids and lipids are selectively secreted in exomeres. Exomeres are having cargoes such as the $\beta$ galactoside $\alpha$ 2,6-sialyltransferase 1 (ST6Gal-I) and amphiregulin (AREG). In this review, we present a comprehensive overview of the recent advances in biogenesis, cargo sorting, membrane trafficking, and functions of EVs, as well as the application of EVs as nanotherapeutic agents. ${ }^{41}$

\section{Biogenesis of EVs}

EVs are secreted by all cells, enabling cell-to-cell communication at close or distant sites. A single cell can secrete more than one type of EVs and can often display heterogeneity within the EVs subtype. ${ }^{12,42}$ Based on their origin, EVs can be divided into several types, including exosomes, ectosomes, MVs, and apoptotic bodies (Figure 1). The mechanisms underlying the biogenesis of different EVs subtypes and the sorting of these molecules remain elusive. In the following section, we discuss some of the mechanisms of biogenesis of the different subsets of EVs.

\section{Isolation and Purification of EVs}

The most common and gold standard method used to isolate EVs is ultracentrifugation from cell culture conditioned medium ${ }^{43}$ and different body fluids including plasma, ${ }^{44}$ serum ${ }^{45}$ saliva ${ }^{46}$ amniotic fluid, ${ }^{47}$ breast milk, ${ }^{48}$ and urine. ${ }^{49}$ Recently, several alternative methods were introduced and utilized for isolation and purification of EVs including differential ultra centrifugation (dUC), Ultrafiltration (UF), and microfluidics ${ }^{50-55}$ Brennan et al reported that a comparative account of isolation and 


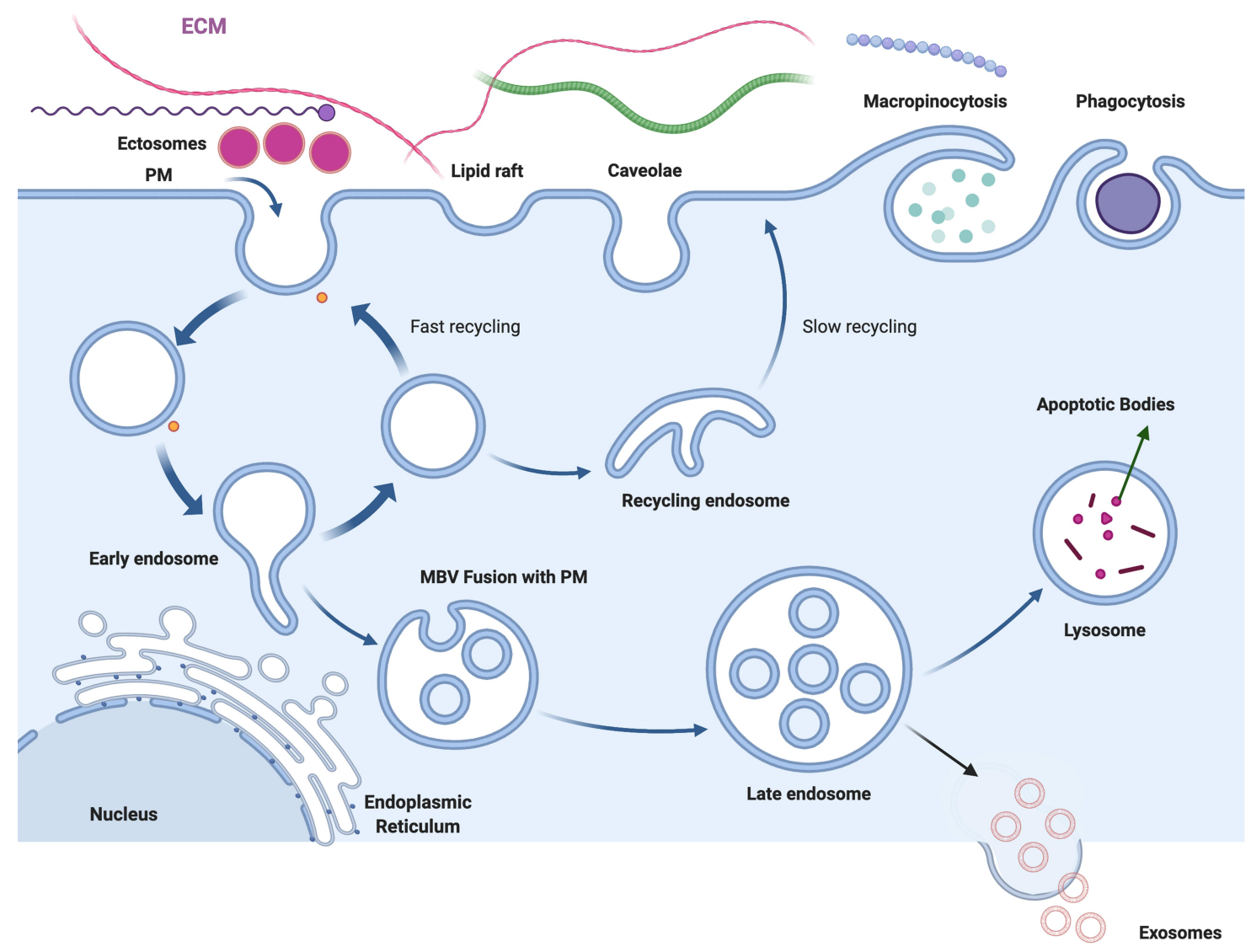

Figure I Schematic presentation of various subtypes of extracellular vesicles such as exosomes, ectosomes and apoptotic bodies, are released into the extracellular environment during physiological and pathological processes.

separation of extracellular vesicles from protein and lipid particles in human serum. ${ }^{56}$ Recently, Liangsupree et al described that a detailed account of isolation and separation techniques based on size-, charge-, and affinity. ${ }^{57}$

\section{Biogenesis of Exosomes}

Exosomes are secreted by various cell types including immune cells, in which exosomes are involved in novel intercellular mechanisms. ${ }^{58,59}$ Mammalian cells, including tumor cells, secrete EVs in the form of a heterogeneous group of membrane vesicles, including both exosomes and MVs. ${ }^{60-62}$ EVs are nanosized bilayered proteolipids present in most biological fluids and help regulate multiple physiological and pathological processes. ${ }^{63}$ Exosomes are one of the best characterized EV subsets and are generated by the internal budding of endosomes, thereby producing multivesicular bodies (MVBs) and subsequently generating intraluminal vesicles (ILVs). ILVs fuse with the plasma membrane, releasing them into the extracellular space as exosomes. ${ }^{64} \mathrm{EVs}$ are classified into exosomes, MVs, or apoptotic bodies based on their mechanism of formation, mode of release from the cells, and size. ${ }^{65}$ ALG-2-interacting protein $\mathrm{X}$ (ALIX) and the tumor susceptibility gene 101 (TSG101) play an important role in the formation of ILVs. ${ }^{66}$ Exosomes range from 50 to $150 \mathrm{~nm}$ in size, are secreted by almost all cell types, and exhibit a characteristic cup-shaped morphology or appear as round vesicles. MVs originate from direct blebbing of the outward plasma membrane and are released into the extracellular matrix. The biogenesis of exosomes is controlled by several factors, including activation of cellspecific receptors and signaling pathways. The fusion of primary endocytic vesicles is the first step in the early endosome formation mediated by clathrin- or caveolindependent or independent pathways. ${ }^{67-69}$ Rab5 is a key regulator of EVs-to-LE conversion in the plasma membrane along with its associate effector VPS34/p150. ${ }^{69}$ Apoptotic bodies are another EVs type formed during cellular blebbing and fragmentation upon apoptosis. ${ }^{65}$ Cancer exosomes are significantly involved in the development and progression of cancer. 
The biogenesis and release of exosomes are regulated by endocytic proteins and lipids. The initial process starts with the budding of the inner membrane of an early endosome, followed by maturation of the MVBs. After maturation, MVBs can be directed for degradation by various enzymes available in the lumen of lysosomes or can travel back to and fuse with the plasma membrane. ${ }^{70}$ The fusion of MVBs with lysosomes is governed by various proteins, including protein tyrosine phosphatase (HD-PTP), the HOP complex (HSP70-HSP90 proteins), the GTPase Rasrelated protein Rab7A, and the members of the soluble N-ethylmaleimide-sensitive factor attachment protein receptor (SNARE) complex (Ca2+-regulated vesicleassociated membrane protein 7 (VAMP7), STX7 syntaxin 7 (STX7), and syntaxin 8 (STX8)), which are considered necessary for MVB fusion with the plasma membrane in leukemic cells. ${ }^{71-73}$ The recycling of MVBs is integrated with the endosomal recycling system and regulated by Rab guanosine triphosphate (GTPases) control, which includes Rab7A, Rab11, Rab27A, Rab27B, and Rab35. ${ }^{74}$ The SNARE complex drives membrane fusion and exosome secretion. The accumulated MVBs dock with the plasma membrane through the trans-SNARE complex, which consists of V-SNARE and T-SNARE on endosomes and plasma membranes, respectively, leading to the release of EVs into the extracellular environment. ${ }^{75,76}$ Furthermore, the generation of exosomes is regulated in an ESCRTdependent and-independent manner, and ceramide can trigger budding of exosome vesicles into multivesicular endosomes (Figure 2). ${ }^{77}$ The ESCRT is responsible for the accumulation and sorting of molecules channeled into ILVs. ${ }^{78,79}$ The main and critical ESCRT complexes such as

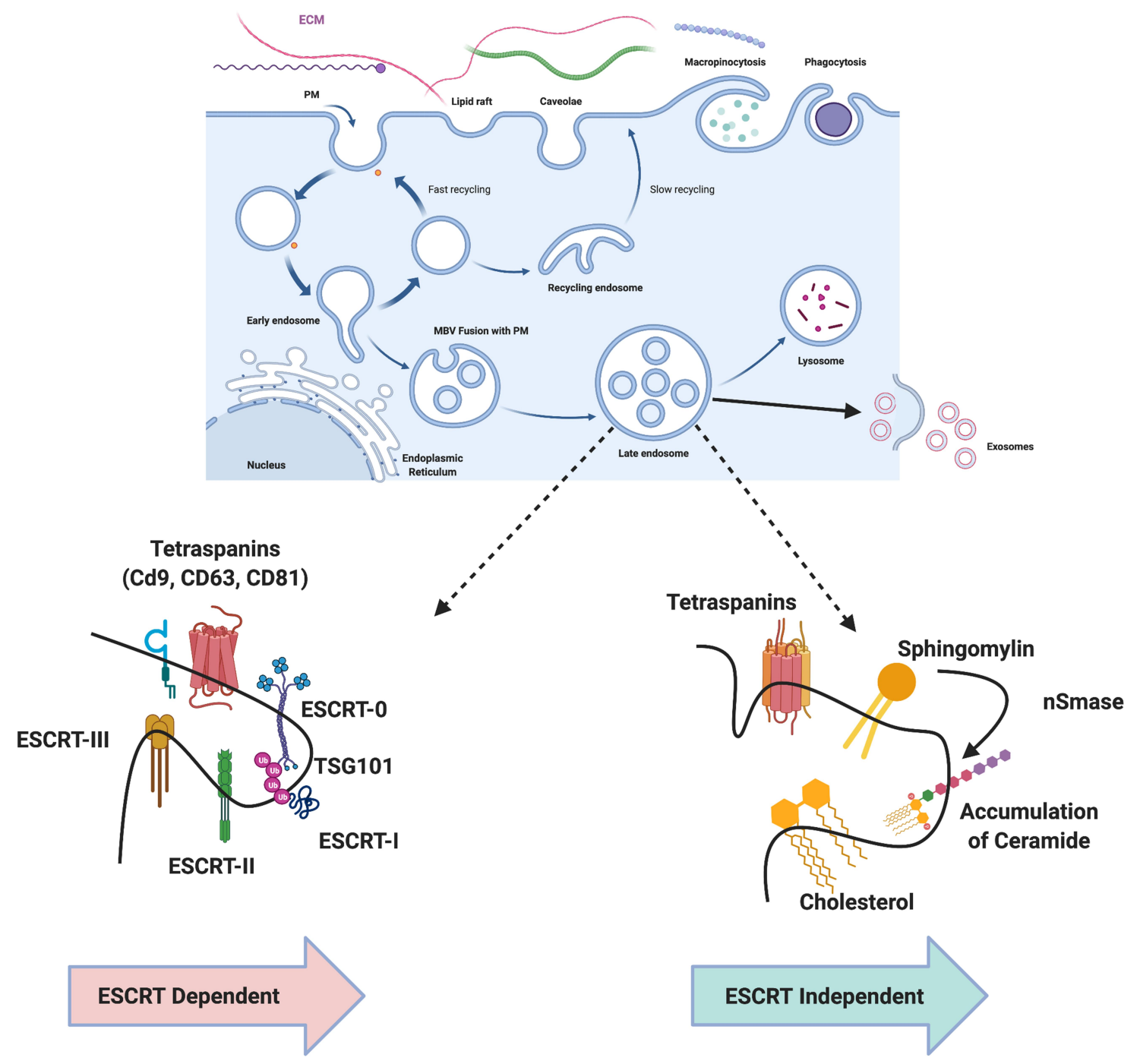

Figure 2 Biogenesis of exosomes by ESCRT dependent mechanism and independent mechanism involved with accessory proteins and lipid dependent pathway. 
ESCRT-0, -I, -II, and-III are responsible for the final delivery of ubiquitinated proteins to the degradation machinery. Exosome protein content and exosome release rate in cancer cells can be altered by the absence of specific ESCRT family members. For example, blocking the expression of ALIX leads to impaired secretion of exosomes in dendritic or muscle cells. ${ }^{25,80}$ The ESCRT machinery comprises four different types of multiprotein subcomplexes: ESCRT-0, ESCRT-I, ESCRT-II, and ESCRT-III, all of which play a significant role in facilitating MVB formation, vesicle budding, and protein cargo sorting [38]. ESCRT complexes are regulated by additional proteins such as ATPase, ALIX, or vacuolar protein sorting-associated protein (VPS4). ${ }^{77}$ ALIX is a marker protein of exosomes that binds to ESCRT-III and delivers unubiquitinated cargoes to the ILVs. ${ }^{81}$ Baietti et $\mathrm{al}^{82}$ reported that ALIX can directly interact with syntenin (syndecan adaptor) via three LYPX L motifs, thereby aiding the budding of the endosomal membrane. The independent mechanism of ESCRT occurs in melanosomes, which are lysosome/endosome-related organelles in melanocytes. For example, PMEL17 is a melanosomal protein that engages its luminal domains along with lipids to contribute to ILV formation. PMEL17 is independent of the ESCRT machinery and exists in clathrin-coated early endosomes, whereas tetraspanin CD63 mediates melanosome membrane invagination in an ESCRT- and ceramideindependent manner. ${ }^{33,83}$ Gurunathan et $\mathrm{al}^{76}$ reported that genes encoding dynamin-related protein (VPS1) and clathrin heavy chain $(\mathrm{CHC} 1)$ are required for producing lowand high-density (LHDSV, HDSV) classes of vesicles. Deletion of these genes in yeast as a model system inhibited HDSV production, yielding LDSVs that contained secreted cargos.

Sphingomyelinases, phospholipase D2 (PLD2), and ARF6 play critical roles in orchestrating the ESCRTindependent pathway, and several other proteins such as Rab27a, Rab27b, and syndecan-syntenin are involved in the formation and secretion of exosomes. ${ }^{84-86}$ Although ESCRT machinery is involved in ILV cargo sorting and formation, other ESCRT-independent processes are involved in exosome biogenesis. ${ }^{87}$ Protein sorting of ILVs is a highly regulated process that is dependent on the ESCRT machinery. Cargo delivery by ESCRT is determined by the ubiquitin checkpoint. ESCRT-0 is responsible for recognizing mono-ubiquitinated proteins via an HRS heterodimer and STAM1/2. ${ }^{88-90}$ Association between ESCRT-I, ESCRT-II, and ESCRT-0 creates a strong recognition domain with high affinity to the ubiquitinated substrates on the part of the endosomal membrane. ${ }^{81}$ ESCRT-III, by joining with the other ESCRT proteins, is responsible for pinching off the membrane and releasing the buds into the endosomes, eventually transferring them to lysosomes for degradation via recognition of deubiquitination of cargoes by deubiquitylating enzymes. $^{91,92}$ Finally, the complex is dissociated by the ATPase VPS4 and its co-factor VTA. ${ }^{89}$ Ceramide-enriched endosomes are highly prone to inward budding and sphingomyelinase (SMase or SMPD2) defection, leading to suppression of ILV formation. ${ }^{22}$

Experimental evidence suggests that purified exosomes contain a rich amount of sphingomyelinase, and inhibition of sphingomyelinase activity leads to the reduction of $\mathrm{EV}$ release; in particular, cholesterol and phosphatidic acid play a critical role in exosome formation. ${ }^{77,93}$ Syntenin increases the level of formation of exosomes associated with the GTP-binding protein, ARF6 and its effector phospholipase (PLD2). ${ }^{82,94}$ The Rab family of small GTPases potentially regulates vesicle trafficking and plasma membrane fusion, subsequently influencing exosome release. Hence, impairment of Rab family members, such as Rab7, Rab11, Rab27a/b, and Rab35, affects exosome release. $^{22,23,82,95-98}$ Rab27a plays significant and specific functions of regulating exosome release from metastatic tumor cells. The shedding of vesicles regulated by these GTPases depends on cell type. ${ }^{99}$ Purified exosomes contain functional microRNAs (miRNAs) and small RNAs, including the class 22-25 nucleotide regulatory miRNAs, which can transfer between circulating cells in humans. ${ }^{100}$ System approaches describe that EVs are composed of many vesicular proteins and that the functional interrelationships and the mechanisms of EVs biogenesis in human colorectal cancer comprised 1491 interactions between 957 vesicular proteins. All these cellular proteins are involved in protein sorting during $\mathrm{EVs}$ formation. Specifically, SRC signaling plays a major role in EVs biogenesis, and inhibition of SRC kinase decreased the intracellular biogenesis and cell surface release of EVs. ${ }^{101}$ Several external factors influence the quantity, content, and release of exosomes through different molecular mechanisms, including cell culture conditions. For example, culture of $\mathrm{N} 2 \mathrm{a}$ neuroblastoma cells in serum-free (OptiMEM) conditions greatly increased the quantity of isolated EVs but did not yield EVs with significant biophysical or size differences compared to those from cells cultured in serum-containing media. Notably, different 
culture conditions induce differential expression of genes and factors involved in EVs biogenesis. ${ }^{102}$ For example, one study addressed the proliferative capacity and selfrenewal properties of chloride intracellular channel-1 (CLIC1) by silencing and overexpressing this gene in cancer stem cells isolated from patients with glioblastoma. The modulation of CLIC1 seems to have no direct role in EV structure, biogenesis, and secretion. ${ }^{103}$ Yang et al ${ }^{104}$ reported that physical stimulation, such as low-intensity ultrasound, increases the expression level of EV/exosome biogenesis and docking mediators in immunosuppressor cells, including myeloid-derived suppressor cells, mesenchymal stem cells (MSCs), B1-B cells, and regulatory $\mathrm{T}$ cells. Extracellular heat shock protein-90alpha (eHSP90 $\alpha$ ) plays an essential role in tumor invasion and metastasis. The level of plasma eHSP90 $\alpha$ determines the conditions of patients with cancer; eHSP90 $\alpha$ accounts for approximately $1 \%$ of the total cellular HSP $90 \alpha$ and is associated with tumor-secreted exosomes. To determine the effect of HSP90 $\alpha$ on exosome biogenesis, the expression of Hsp90 $\alpha$ was inhibited by CRISPR-cas9 knockout. Knockout of Hsp90 $\alpha$ did not affect the overall distribution and quantity of secreted exosomes but increased the expression level of exosome-associated CD9 and decreased the expression level of exosome-associated TSG101, ALIX, and CD63. ${ }^{105}$

Leptin regulates the mechanisms of biogenesis and release of exosomes and also increased the number of MVBs and release of MVBs in the cytoplasm of breast cancer cells. ${ }^{106}$ Hitomi et al reported that DNA damage activates the ceramide synthetic pathway leading to an increase in senescence-associated EVs (SA-EV) biogenesis ${ }^{107}$ The EVs biogenesis pathway, which is associated with the autophagy-mediated degradation pathway, leads to inhibition of apoptosis. The SA-EV pathway may play a significant role in cellular homeostasis, particularly in senescent cells. Stress conditions such as hypoxia, serum starvation, acidosis, different cell types, and nanoparticle exposure induce various levels of exosome biogenesis and release in cancer cells. Recently, Gurunathan et al discussed the various factors involved in biogenesis, functions, therapeutic and clinical implications of exosomes. ${ }^{108-110}$

\section{Biogenesis of Microvesicles (MVs)}

Biogenesis of MVs is directly derived from the plasma membrane and shares many of the same proteins involved in exosome biogenesis., ${ }^{2111,112} \mathrm{MVs}$ are involved in various physiological functions, including altering the extracellular environment, intercellular signaling, and facilitating cell invasion through cell-independent matrix proteolysis. ${ }^{34,65,113}$ Furthermore, MVs play a critical role in various aspects of physiology, including tumor invasion and angiogenesis. MVs can transfer bioactive molecules, including proteins, DNA, mRNA, and miRNA, and can thereby modify the extracellular milieu and proximal and distal recipient cells. ${ }^{43,70}$ The biogenesis and release of MVs is different from that of exosomes and is regulated by multiple mechanisms. MVs are generated from sites of high membrane blebbing, and their formation is stimulated in cells invading through compliant matrices. ${ }^{65,114-116}$ The vertical distribution of MVs is attributed to changes in plasma membrane components. MV formation is a unique mechanism of EVs formation compared with that of exosomes and regulated by ARF6 and RHOAdependent rearrangement of the actin cytoskeleton. ${ }^{117}$ MV biogenesis comprises vertical trafficking of molecular cargo to the plasma membrane, a redistribution of membrane lipids, and the use of contractile machinery at the surface to allow vesicle pinching. ${ }^{65}$ Shed MVs are distinct from other populations of cell-derived EVs, including exosomes. The two populations differ in size, cargo, and mechanism of formation, and the size of MVs can cover several microns. The ESCRT complex is involved in MV biogenesis. ARF-6 plays a critical role in the trafficking of cargo to the cell surface in MVs. ${ }^{118} \mathrm{MV}$ release is aided by several proteins, including TSG101, ALIX, and ARRDC1, and cytokinetic abscission is performed using ESCRT-III and ALIX. ${ }^{119}$ For instance, MV stimulation and release are facilitated by the activation of A-SMase (acid sphingomyelinase) in astrocytes and glial cells, and ceramide and cholesterol play significant roles in MV formation. ${ }^{120}$ The extracellular concentration of calcium plays a significant role in MV structure, whereas an increased level of calcium induces membrane phospholipid scrambling and improves the formation of MVs by increasing the level of vesiculation ${ }^{121,122}$ and also increases MV formation in erythrocytes and platelets. ${ }^{123}$ G-protein coupled receptor 30 (GRP30) stimulates the formation of extracellular matrix metalloproteinase inducer (EMMPRIN)-containing MVs from uterine cells. ${ }^{124}$ The prominent plasma membrane lipid cholesterol plays a critical role in MV formation, whereas a lack of cholesterol leads to reduced levels of MV formation. ${ }^{125}$ Ceramide, a cone-shaped lipid, is known to play a vital role in the genesis of EVs, including MVs, and is responsible for enhancing membrane bending 
for the formation of MVs. ${ }^{126}$ Once the MVs are loaded with cargo and pinched by acto-myosin contraction, which is a tightly regulated process, it is necessary to enhance and inhibit the process of blebbing and pinching. These processes are regulated and governed by Rho family GTPases. ${ }^{114,117}$ MV formation is promoted by RhoA activity through the downstream kinases ROCK, ERK, and cofilin phosphorylation. ${ }^{114,117}$ Hypoxia promotes MV formation via cellular processes mediated by hypoxiainducible factors and Rab22a. ${ }^{127}$ Large oncosome (LO) formation was enhanced by suppression of the actinnucleator diaphanous-related formin 3 (DIAPH3), the activation of EGFR, overexpression of membrane-targeted Akt1 caveolin-1, and stimulation with heparin-binding EGF-like growth factor combined with p38MAPK inhibition. $^{128,129}$

Stachowiak et al suggested that another mechanism of MV formation due to membrane curvature results in bending of the plasma membrane caused by overcrowding at the cell periphery; lateral pressure generated through proteinprotein interactions also contributed to membrane shape changes, which may play a role in de novo $\mathrm{MV}$ formation. ${ }^{130}$ The membrane curvature is significantly controlled by phospholipids to induce a discrete membrane curvature. Furthermore, aminophospholipid translocase (flippase and floppase) recruitment facilitates the formation of membrane curvature during MV formation. ${ }^{131}$ Further studies demonstrated that the accumulation of extraneous membrane at microvillar tips acts as a source of MVs shed into the gut lumen in a myosin-1a dependent fashion, and increased production of hyaluronan can lead to the release of MVs from the ends of long, microvilli-like projections. ${ }^{132,133}$ All these studies demonstrate that under certain conditions, pinching of microvilli or other cell protrusions may be another mechanism for MV release. Global proteomic analysis revealed that purified MV from human colorectal cancer cells contains 547 MV proteins, 49 of which, including annexins, ADP-ribosylation factors, and Rab proteins, are involved in the biogenesis of MV, with 28 proteins involved in tumorigenesis via promotion of migration, invasion, and growth of tumor cells, immune modulation, metastasis, and angiogenesis. ${ }^{134}$ The delivery of MV cargo, such as the membrane-type 1 matrix metalloprotease (MT1-MMP) to shedding MVs was regulated by v-SNARE and VAMP3. Hepatocellular carcinoma cells shed more MVs than normal hepatocytes. miR-200a was able to inhibit MV formation and regulation of secretion by targeting gelsolin and altering the cytoskeleton. Furthermore, miR- 200a inhibits the proliferation of adjacent cells by inhibiting the release of MVs. These findings suggest that miR-200a governs MV biogenesis in hepatocellular carcinoma progression. ${ }^{135}$ Calcium concentration plays a significant role in EV biogenesis For example, the efficacy of vesiculation is significantly enhanced in malignant MCF-7 cells compared with that in non-malignant hCMEC-D3 cells due to increased levels of free cytosolic $\mathrm{Ca}^{2+}$. Storeoperated calcium entry plays an essential role in the maintenance of $\mathrm{EV}$ biogenesis after depletion of stored $\mathrm{Ca}^{2+} \cdot{ }^{2} 6$

\section{Biogenesis of Apoptotic Bodies}

Apoptotic bodies are a class of EVs with various sizes between 1000 and $5000 \mathrm{~nm}$, formed exclusively during programmed cell death. ${ }^{137}$ Morphological changes such as membrane blebbing, membrane protrusion, and release of apoptotic bodies are characteristic features of apoptotic cells undergoing apoptosis. ${ }^{138}$ The number of apoptotic bodies produced per cell is different from that produced by EVs; the average number of apoptotic bodies was found to be $12.87 \pm$ $3.23 / \mathrm{h}$ and EVs by MSCs were found to be in the range of 2900 per cell. ${ }^{139,140}$ The membrane of apoptotic bodies reflects the main changes occurring on the cell surface of apoptotic cells. In particular, apoptotic cells express markers that promote their removal by surrounding cells or macrophages before cell membrane rupture. ${ }^{141}$ CD47 plays critical role in apoptotic bodies formation, for example, calreticulin, an "eat me" ligand is physiologically silenced by the CD47 "don't eat me" ligand; and only expressed by cells and ApoBDs when CD47 is down regulated. ${ }^{142}$

Apoptotic bodies enable the removal of apoptotic cells by phagocytes and modulate the immune system. ${ }^{138,143}$ Apoptotic bodies contain typical characteristic markers of apoptotic bodies, such as phosphatidylserine. ${ }^{144}$ The apoptotic volume decrease (AVD) is associated with membrane blebbing, which is a critical and primary event in apoptotic body formation. ${ }^{145}$ AVD starts within $0.5-2 \mathrm{~h}$ after apoptosis induction accompanied by caspase activation and mitochondrial dysfunction. ${ }^{146}$ The efflux of osmolytes, mainly ions, via transporters and channels is an indispensable process in AVD. ${ }^{147}$ AVD occurs in two different processes, including cytochrome $\mathrm{C}$ release from the mitochondria and cytoskeleton organization. The cargo of apoptotic bodies contains chromatin, small numbers of glycosylated proteins, large amounts of low molecular weight RNA, and intact organelles such as mitochondria, as well as nuclear fragments, microRNAs, RNA, and DNA. ${ }^{15,148,149}$ The diversity of the cargo content of apoptotic bodies influences their 
physiological properties. Furthermore, apoptotic bodies are subdivided into two groups: DNA-carrying apoptotic bodies and cytoplasm-carrying apoptotic bodies. In particular, DNA carrying apoptotic bodies contains 5-phosphorylated bluntended DNA. ${ }^{150}$ The characteristic feature of apoptotic bodies is the presence of externalized phosphatidylserine and a permeable membrane, which express phagocytosispromoting signals such as calreticulin ${ }^{142}$ and calnexin. ${ }^{151}$ Apoptotic bodies are used to express chemokines and adhesion molecules such as CX3CL1/fractalkine and ICAM3. The expression of MHC class II molecules facilitates direct antigen presentation to $\mathrm{CD} 4^{+} \mathrm{T}$ cells and activation of immunological memory. ${ }^{138}$

\section{Biogenesis of Ectosomes}

The biogenesis of ectosomes (diameter $50-500 \mathrm{~nm}$ ) is different from other EVs; however, the difference between exosomes and ectosomes is not unique. Ectosomes are generated by almost all cell types and play a role in intercellular communication. The secretion of cargoes by ectosomes occurs by the accumulation of cargo at the cytosolic surface of the plasma membrane. Ectosomes are then secreted through the budding of the outward cell membrane and are released into the extracellular matrix. ${ }^{152}$ The formation of ectosomes depends on local microdomains assembled in the plasma membrane of ectosomes. The surface and luminal cargoes are heterogeneous when comparing vesicles released by different cell types or by single cells in different functional states. The lumen and cytosol of ectosomes contain similar levels of heat shock proteins and several enzymes, and the interactions between the specific proteins and the ectosome lumen are mediated through the presence of protein anchoring, palmitoylation, myristylation, sumoylation, and high-order polymerization. Biogenesis of ectosomes is due to the rearrangement of the asymmetric membrane consisting of a phospholipid layer ${ }^{153,154}$ (Figure 3). Secretion and control of cargo assembly of ectosomes regulated by the small GTPase ARF6 and the small GTPase act through the contraction of cortical actin under the plasma membrane. ${ }^{114}$ The membrane of ectosomes contains high levels of cholesterol, sphingomyelin, and ceramide. ${ }^{112,155}$ However, membrane reorganization can be influenced by $\mathrm{Ca}^{2+}$-dependent enzymes, and ectosomes consist of other proteins. ${ }^{156}$ Ectosome structures contain abundant levels of various cargoes, including miRNAs, mRNAs, and noncoding RNAs. ${ }^{148}$

\section{Biogenesis of Oncosomes}

Oncosomes are 100-400 $\mathrm{nm}$ vesicles are formed by blebbing off the plasma membrane of tumor cells and can form large or small vesicles. ${ }^{129,157}$ Large oncosome vesicles are usually larger than MVs and are typically associated with

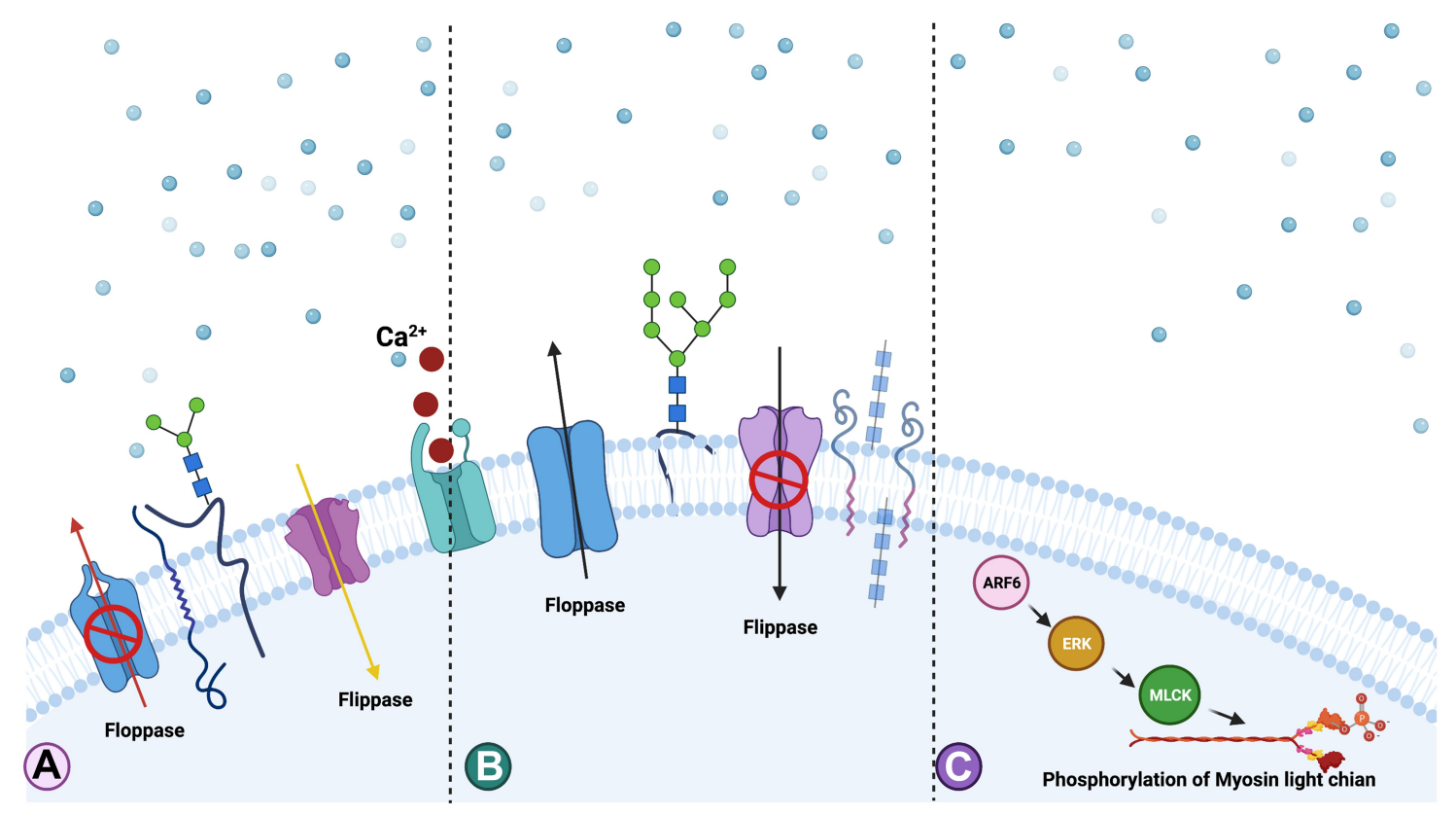

Figure 3 Mechanism of biogenesis of ectosomes. Increased level of accumulation of $\mathrm{Ca}^{2+}$ at the plasma membrane and involvement of translocase enzymes and proteins such as ADP-ribosylation factor 6 (ARF6), extracellular signal regulated kinases (ERK) and phosphorylation of myosin light chain kinase (MLCK). (A) Extensive accumulation of $\mathrm{Ca} 2+$ at the PM region causes the imbalance of the phospholipids orientation. (B) Role of flippase and floppase to maintains the phospholipids symmetry. (C) ARF6 activates ERK followed by the phosphorylation of myosin light chain which stimulates the budding of ectosomes from the PM. 
cell motility and the release was regulated by various structural proteins promotes extrusion and scission of the plasma membrane. ${ }^{18,24,138,158,159}$ Tumor cells spontaneously release oncosomes that contain metalloproteinases with proinvasive properties. ${ }^{34,128}$ The release of oncosomes, and other EVs, is induced by stimuli, leading to an increase in intracellular calcium and cytoskeleton remodeling. ${ }^{160}$ In some cases, large oncosomes, typically $1-10 \mu \mathrm{m}$ in size can be formed. ${ }^{161}$ Di Vizio et al $^{129}$ reported that amoeboid migration of metastatic prostate cancer cells triggered the production of gigantic EVs (1000-10,000 nm), which emanate from large protrusions of the cellular plasma membrane. These large vesicle formations were dependent on cellular transformation, including the activation of AKT1 and EGFR pathways, and were associated with abnormal assembly of molecular cargo, such as proteins and nucleic acids, and were subsequently called "large oncosomes" (LOs). Oncosomes are byproducts of non-apoptotic cells when a large portion of the cellular membrane is shed from the outward membrane during blebbing events. ${ }^{162}$ The shedding process is induced by silencing of the cytoskeletal regulator diaphanous-related formin-3 (DIAPH3) protein, by the overexpression of oncoproteins caveolin-1 (CAV-1_, heparinbinding epidermal growth factor (HB-EGF), myristylated Akt1 (MyrAkt1), or activation of the EGFR and AKT1 pathways. ${ }^{18,161,163-165}$ Depolymerization of the actin cytoskeleton by overexpression of the small GTPase $\mathrm{ARF}^{34}$ and/or loss of the actin-nucleating DIAPH3 play critical roles in efficient production of large PM-derived oncosomes from tumor cells. ${ }^{129}$ ARF6 appears to be involved in targeting pre-miRNAs to oncosomes along with miRNA processing machinery. ${ }^{159}$ These oncosomes serve as carriers for bioactive molecules and abnormal and transforming macromolecules, including mRNAs, microRNAs, lipids, and biologically active proteins. Oncosomes contain increased levels of potential biomarkers, such as membrane-localized cytokeratin-18 and lower levels of tetraspanins CD9, CD63, and CD81. Cytokeratin can be used as a marker to distinguish tumorderived oncosomes, which are completely different from other EVs. ${ }^{18}$ The unique composition of oncosomes facilitates the transfer of signals to specific target cells, modulates the primary and secondary tumor microenvironments, and serves as a master regulator of tumor growth, inflammation, extracellular matrix remodeling, angiogenesis, and inhibition of innate and adaptive immune responses. ${ }^{166}$ Oncosomes control tumor progression by degrading the extracellular matrix and promoting intravasation via endothelial permeabilization factors. ${ }^{128}$ Oncosomes are able to transfer RNA and alter epigenetic, reprogramming, and migration in endothelial cells. Tumorderived oncosomes induce extravasation and colonization by endothelial leakage and can export specific oncogenic cargo to other tumor or stromal cells. LOs derived from DU145 cells with DU145R80 suggests that $\alpha \mathrm{V}$-integrin on the LO surface increases adhesion and invasion of recipient cells via AKT. ${ }^{167}$

\section{Cargoes Sorting and Membrane Trafficking of EVs}

Membrane trafficking is an essential process that includes vesicle formation, cargo sorting, and fusion. The mechanism of cargoes sorting involved various post translation modification processes can sort proteins into EVs (Figure 4). Vesicle formation and fission are critical for specific cargo cap structures and transport. The compartmentalization of the cytoplasm into distinct membranes is a unique and distinct feature of eukaryotic cells compared to prokaryotic cells and is an essential process for cellular processes in eukaryotic cells. The release of cargo from EVs into recipient cells consists of various mechanisms, including fusion with the plasma membrane, ${ }^{168,169}$ kiss and run fusion with the endoplasmic reticulum, ${ }^{170}$ fusion with the endosome membrane ${ }^{171}$ and endosomal rupture. ${ }^{2,125,171}$ The regulation of these membrane-mediated processes involves a complex array of protein and lipid interactions. For example, membrane-bound EVs play a critical role in intercellular communication and potential biomarkers because of the presence of a variety of cargoes, including annexin II, heat shock proteins, and heteromeric $\mathrm{G}$ protein Gi2 $\alpha$ in the exosome lumen as well as membrane proteins, such as MHC class II complexes, integrins, and tetraspanins. ${ }^{172}$ Furthermore, EVs contain various types of lipids such as ceramide, PS, sphingomyelin, gangliosides, desaturated lipids, and PC; however, their specificity and abundance depends on the cell of origin. ${ }^{173,174}$ In addition, EV RNA, glycans, particularly $\alpha-2,6$-sialic acid, complex N-linked glycans, polylactosamine, and mannose also act as EV markers. ${ }^{175-177}$

Although several studies have focused on cargo sorting, the specific EV cargo sorting mechanisms are still unclear. ${ }^{11,178}$ Generally, two major mechanisms have been proposed to sort proteins into EVs: ubiquitin-dependent ESCRT sorting and tetraspanin-enriched microdomains. ${ }^{35,179}$ 


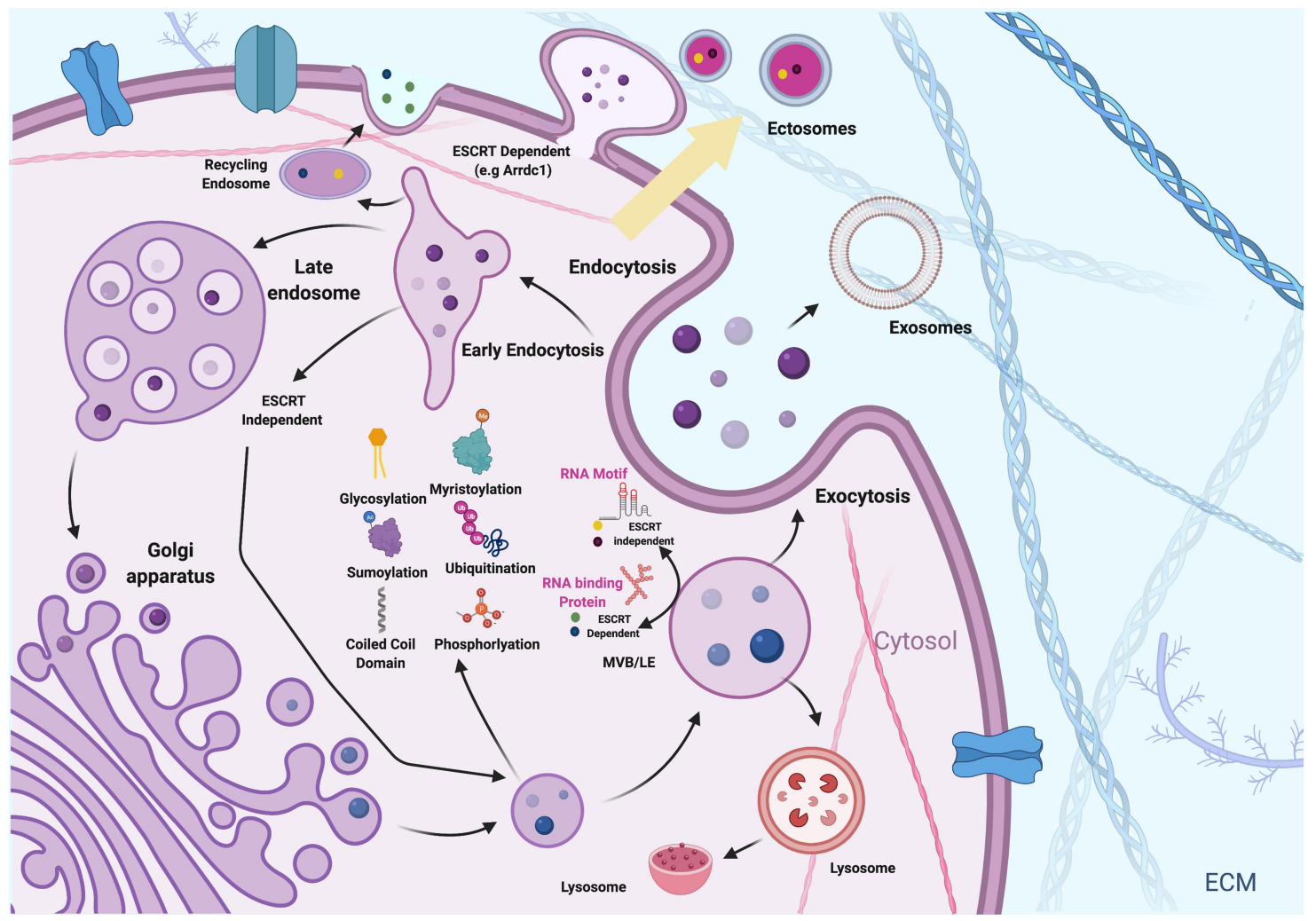

Figure 4 Sorting of cargoes into EVs. Proteins and RNA can be packaged into the EVs by various mechanisms including ubiquitination, phosphorylation, myristoylation, glycosylation and sumoylation.

EVs consist of a wide range of biomolecules, and all these cargoes are sorted into EVs by different pathways, including ESCRT-, tetraspanin-, and lipid-dependent mechanisms; the functional aspects and destination of cargo of EVs depends on the loaded components. The ESCRT complex (ESCRT-0/-I/-II /-III) machinery plays a vital role in sorting ubiquitinated proteins into vesicles ${ }^{180}$ and self-associates at the membrane of endosomes by interacting with its subunit hepatocyte growth factor-regulated tyrosine kinase substrate. The c four multi-protein ESCRT complex and additional accessory proteins are involved in ubiquitinated cargo sorting. In the first stage, the Hrs compartment interacts with TSG101, which facilitates the formation of ESCRT-II through VPS28 (ESCRT-I)-VPS36 (ESCRT-II) interaction. ${ }^{181-183}$ In the late stage, the ESCRT-III complex is recruited and activated by VPS25 (ESCRT-II)-Vps20 (ESCRT-III) interaction. ${ }^{184}$ ESCRT-III plays a significant role in EV formation by initiating membrane deformation and inward budding. ${ }^{185,186}$ ALIX is also a crucial aspect of the ESCRT complex machinery and is recruited by charged multivesicular body protein $4 \mathrm{a}$ (CHMP4), which is involved in the stabilization of the complex. ALIX can act as an adaptor protein that recruits cargo into developing EVs in a ubiquitin-independent manner. ${ }^{187,188}$
Furthermore, ALIX is also involved in miRNA recruitment by interacting with the Argonaute 2 (AGO2) protein complex. ${ }^{189}$ Lysobisphosphatidic acid is involved in the initiator of an additional recruitment pathway by interacting with syntenin, the cytoplasmic adaptor protein through membrane deformation. Syntenin binds syndecan and other proteins via its PDZ domain The ALIX-syntenin-syndecan complex can sort specific cargo into EVs. ${ }^{82,190}$ The syndecan heparin sulfate domain seems to be involved in the sorting and formation process and is cleaved and activated by the modulator-enzyme heparanase. ${ }^{191}$ ILV formation within MVB not only depends on ESCRT components, but also on the ESCRT-independent mechanism via tetraspanin-dependence. Interestingly, the ESCRT-independent mechanism produces smaller vesicles than that of the ESCRT-dependent mechanism. For instance, a lack of CD63 causes a decrease in smaller vesicles of less than $40 \mathrm{~nm} .{ }^{192,193}$ Another mechanism of EV release and protein recruitment is also influenced by posttranslational modifications by ubiquitin-like proteins. For instance, posttranslational modification of ISGylation by interferonstimulated gene 15 (ISG15) is induced by interferons (IFN causes the accumulation and degradation of TSG101), resulting in impaired exosome secretion and subsequent alterations 
in EV cargo. ${ }^{194,195}$ Although the sorting and recruitment of proteins is passive in MVs, they are still controlled by the ESCRT-associated ATPase VPS4, as well as TSG101 through interaction with arrestin domain-containing protein 1 (ARRDC1), which is responsible for the relocation of TSG101 via ubiquitin E2 variant (UEV)-motif recognition from the endosomal membrane. ${ }^{196}$ According to ExoCarta and Vesiclepedia, EVs contain more than 10,000 unique proteins from human cells, tissues, and bodily fluids. ${ }^{197}$ Although ESCRT is involved in protein sorting, some proteins are packaged during biogenesis. For example, ALIX and TSG101 are selectively packaged into EVs. ${ }^{198}$ The selective mechanism of protein cargo sorting is controlled by posttranslational modifications, including ubiquitination, SUMOylation, NEDDylation, and ISGylation (Figure 4). ESCRT complexes are responsible for sorting monoubiquitinated transmembrane cargos into ILVs. ${ }^{199,200}$ ESCRT-0, ESCRT-1, and ESCRT-II interact with appropriate ubiquitinated cargos in a tightly coordinated manner and recruit them to the late endosomal membranes/MVBs. ESCRT-III, along with its accessory proteins, promotes membrane scission. ${ }^{200,201}$ The assembly of the ESCRT-0 protein Hrs with phosphatidylinositol 3-phosphate (PI(3)P) allows Hrs to begin the membrane recruitment process. Ubiquitinated Hrs and STAM1/2 enhance cargo sorting into endosomes The ubiquitinated Nedd4 family proteins not only regulate the early steps of EV biogenesis via ubiquitination but are also recruited and released via EVs. ${ }^{202}$ To prove the importance of ubiquitination in cargo sorting, studies have reported that ubiquitination of divalent metal ion transporter (DMT1) by ARRDC1 regulates arrestin-dependent cargo sorting into EVs and subsequent release of EVs. ${ }^{203,204}$ However, ubiquitins, such as mahogunin, ubiquitinate TSG101 and thus regulate endosomal trafficking. ${ }^{205,206}$ The ESCRT-independent mechanism of protein sorting involves mono-and poly ubiquitinated proteins in MVBs. ${ }^{207}$ ISGylation plays an important role in cargo sorting into EVs. For example, ISGylation of TSG101 promotes aggregation and degradation and attenuates EV secretion. ${ }^{194,208}$

\section{Sorting of RNAs into EVs}

The biogenesis and sorting of EVs from various types of cells exhibit distinct RNA profiles, comprising messenger RNAs and non-coding RNAs (ncRNAs). In particular, ncRNAs play a significant role in the tumor microenvironment and premetastatic niches. Recent studies have indicated that EV-RNAs are responsible for essential functional cargoes in modulating hallmarks of cancers. ${ }^{209}$ Sorting of
RNAs into EVs regulated by particular sorting machineries involves RNA binding proteins (RBPs) and their associated partners, which can target RNAs to the site of EVs generation and protect them from degradation. ${ }^{210,211}$ The lack of Dicer enzyme has an inhibitory effect on miRNA levels in the exosomes rather than in the producer cells. Overexpression of miRNA increases the levels of miRNA in exosomes; hence, the expression level of miRNAs is the first layer of regulation of miRNA sorting into exosomes. ${ }^{212}$ AGO2 may serve as an important transferring machinery and control the sorting of specific miRNAs for EVmiRNAs. For example, AGO2 knockout reduces the loading of several preferentially secreted miRNAs into EVs, such as miR-451 and miR-150, and also decreases the exosomal content of small RNAs. ${ }^{213,214}$ The release of exosomal miRNAs such as miR-146a and miR-155 is highly influenced by the knockdown of GW182. Inhibition of ALIX expression leads to a decrease in the level loading efficacy of secreted miRNAs into EVs, but not the release of EVs. ${ }^{189}$ Similarly, VPS4A controls the release of oncogenic miRNAs in exosomes. ${ }^{215}$ RBPs are involved in miRNA sorting by recognizing specific RNA motifs. Villarroya-Beltri et $\mathrm{al}^{216}$ demonstrated that hnRNPA2B1 controls exosomal sorting with the GGAG motif. Posttranslational modification of hnRNPA2B1 increases the sumoylation of hnRNPA2B1 and the rate of binding with miRNAs and localization into exosomes. CAV-1 forms a complex with hnRNPA2B1 and induces hnRNPA2B1 OGlcNAcylation via tyrosine-14 phosphorylation, thereby directing hnRNPA2B1-bound miR-17/93 into MVs; hnRNPA2B1 thus enhances its binding to specific miRNAs and incorporation into MVs. ${ }^{217}$ SYNCRIP displays the GGCU-motif-specific exosomal sorting capacity of miRNAs. ${ }^{218}$ The presence of $\mathrm{Ca}^{2+}$ influences sorting of miRNAs into EVs in a sequence-independent manner. ${ }^{219}$ A study reported that inhibition of nSMase 2 prevents the sorting of multiple miRNAs such as miR-451a, miR-122, and miR-146a into EVs and that inhibition of sphingosine kinase 2 (SPHK2) reduces exosomal loading of miRNA21. ${ }^{220-223}$ Another study found that miRNAs regulate mRNA targeting into EVs by specifically binding to zipcode RNA sequence motifs. For example, miR-1289 directly binds to the inserted zipcode on EGFP mRNA and enhances the efficiency of zipcode-mediated EGFP mRNA sorting into MVs. ${ }^{224}$ The RNA content of EVs is influenced by several factors, including the subpopulation of EVs, cell type, and the physiological or pathological state of producing cells as well as their received stimuli. RNA 
loading into EVs can occur either by active or passive mechanisms and also depends on RBPs and their partners as well as RNA motifs and modifications, with a combined effect on stabilization and/or subcellular localization of EVRNAs. Post-translational modification of RBPs increases their affinity towards MVs and RNAs, which are major regulators of exosomal sorting, and RBP-mediated RNA incorporation into EVs depends on ceramide generation. Furthermore, specific motifs and structures of RNAs play important roles in EV-RNA secretion by mediating RNARBP and RNA-RNA interactions. ${ }^{209}$

The packaging of certain RNAs is sorted into subsets of $\mathrm{EVs}$; for instance, the larger the EV, the more likely it is to incorporate a given cytoplasmic entity, whereas small EV (sEV) content is more likely to be restricted to molecules in close proximity to membranes. Data from studies suggest that large EVs (lEVs) and their parent cells have highly correlated RNA expression profiles, whereas the RNA expression of sEVs differs significantly from that of the source cell. ${ }^{225,226}$ Similarly, larger cargo, such as full-length mRNAs with associated proteins, can be easily sorted into larger vesicles and smaller cargoes sorted into SEVs without efficient packaging mechanisms. Exosomes secreted from cancer cells are involved in tumor progression; one strategy is to decrease exosomal miRNA secretion. To demonstrate this concept, the authors designed small interfering RNA (siRNA)-loaded nanoparticles to silence the SPHK2 gene using nanoparticles such as lipid (2E)-4-(dioleostearin)-amino-4-carbonyl- 2-butenoic (DC) and chitosan and introduced these into hepatocellular carcinoma cells. Nanoparticle-mediated silencing of the SPHK2 gene reduced miRNA-21 sorting into exosomes, contributing to the inhibition of tumor cell migration and tumorigenic function of exosomes to normal liver cells as well as in a xenograft mouse model. ${ }^{220}$ The Figure 5 shows various steps involved in the process of isolation of extracellular vesicles from condition medium and isolated EVs depicted various types of cargos packaged into EVs. $\mathrm{CD} 31^{+}$extracellular vesicles from patients with type 2 diabetes of blood circulating miRNAs signature serving as tool to detect T2DM complications. Extracellular vesicle (EV)shuttled miRNAs were isolated using immunomagnetic beadbased method, which are considered to be a CD $31^{+}$EVs were also positive for a range of markers typical of both platelets and activated endothelial cells. ${ }^{227}$

\section{Impact of Post-Translation Modification on Cargoes Sorting}

Proteomic analysis revealed that phosphorylation is not only involved in selective cargo sorting, but also protects against degradation. Phosphorylation of the proline-rich domain and mono-ubiquitination of FasL results in the phosphorylated protein being potentially sorted into EVs. ${ }^{228}$ Similarly, phosphorylated Tau at Thr-1801 is packed and sorted into EVs, and phosphorylated annexin A2 is protected from endosomal degradation, which facilitates its incorporation into the EV membrane. ${ }^{229,230}$,

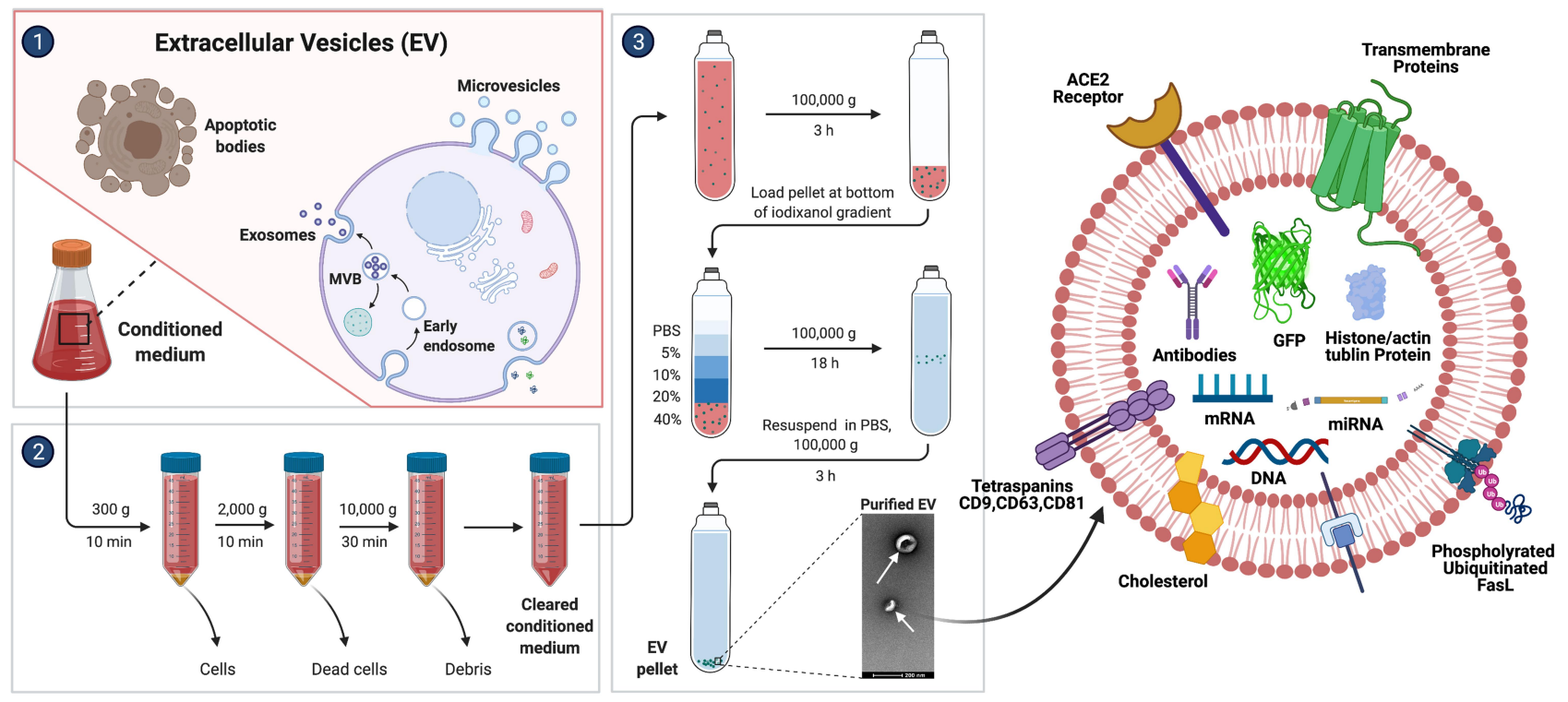

Figure 5 Schematic representation of isolation of EVs from conditioned medium using various centrifugation steps and isolated EVs displayed packaging of cargoes DNA, proteins, miRNA, antibodies, tetraspanins, histone, actin and tubulin. 
Carbohydrate modification of VIP36 polyLacNac and high mannose expedites sorting of the modified protein into Golgi-derived vesicles. ${ }^{177,231,232}$ Citrullination is also involved in sorting of various types of protein cargo into EVs. ${ }^{233,234}$ Myristylation of the yeast cytoplasmic protein Tya results in this being packaged into EVs, which plays a highly efficacious role in the formation of ectosomes. ${ }^{235}$ The oxidation process is also involved in the sorting of cargo into EVs. Oxidized $\gamma$-synuclein is found in exosomes and is released into the extracellular environment. $^{236}$ The role of the WW domain in sorting of cargoes into EVs was confirmed by location of NEDD4 family proteins, such as NEDD4, NEDD4-2, and ITCH, into EVs by fusion of the WW domain with proteins targeted to EVs. ${ }^{202,237}$ Similarly, proteins found in EVs contain a significant level of coiled coil domain in LIM1215 colorectal cancer cell-derived EVs. ${ }^{238}$

\section{Inhibition of EVs Release}

EVs are major players in several pathophysiological conditions and are also involved in disease development and progression. ${ }^{18,239,240}$ For instance, many pharmacological agents are known to inhibit the release of EVs, which is a recent development in therapeutic approaches. Inhibitors of the secretion of cancer exosomes promote cancer progression and metastasis. ${ }^{241}$ The best approach is to identify particular inhibitors that can selectively affect EVs involved in pathology, but not those that perform necessary physiological roles. ${ }^{242}$ These inhibitors could provide an avenue for targeted therapy. $\mathrm{Im}$ et $\mathrm{al}^{241}$ reported that sulfisoxazole inhibits the secretion of sEVs from breast cancer cells by interfering with endothelin receptor A (ETA). A chemical inhibitor, GW4869, potentially inhibits ceramide-induced secretion of exosomes, and a specific siRNA resulted in reduced secretion of miRNAs. ${ }^{243}$ Wei et al $^{244}$ reported the direct correlation between inhibition of exosome release suppressing proliferation of human breast cancer cells. For example, a breast cancer cell line (MCF-7) treated with shikonin decreased the level of secreted exosomes and inhibited cell proliferation. Sodium nitrite $\left(\mathrm{NaNO}_{2}\right)$ reduced hypoxia $\left(1 \% \mathrm{O}_{2}\right)$ induced production of EVs in endothelial (HECV) cells compared with that from cells exposed to normoxia or hypoxia. ${ }^{245}$ Overmiller et $\mathrm{al}^{246}$ reported that $\mathrm{EV}$ release is modulated by the C-terminal fragment of desmoglein 2 (DSG2). Evidence suggests that overexpression of DSG2 increases $\mathrm{EV}$ release and mitogenic content, including EGFR and c-SRC. Inhibiting ectodomain shedding of
DSG2 with the matrix metalloproteinase inhibitor GM6001 resulted in the accumulation of full-length DSG2 in EVs and reduced EV release. When human prostate cancer (PC3) cells and MCF-7 cells were exposed to potential exosome and MV (EMV) biogenesis inhibitors, EMV release was inhibited. ${ }^{247}$ The effect of MMP inhibitors on the release and proteolytic activity of monocyte/macrophage-derived microparticles in peripheral blood mononuclear cells was demonstrated by stimulation with the calcium ionophore A23187. The findings revealed that MMP inhibitors significantly prevented MP shedding in a concentration-dependent manner by reducing intracellular $\mathrm{Ca}^{2+}$ levels. ${ }^{248}$

\section{Promotion of EVs Release}

Low $\mathrm{pH}$ conditions influence exosome release and uptake by cancer cells. At low $\mathrm{pH}$ conditions, exosome release and uptake were higher than in buffered conditions, and exosome uptake by melanoma cells occurred by fusion. ${ }^{168}$ Additional factors, such as detachment of adherent cells from various substrata, can induce rapid and substantial secretion of exosomes. Methyl-beta-cyclodextrin inhibits the internalization of exosomes by disrupting lipid rafts. ${ }^{249}$ Overexpression of hyaluronan synthase 3 (HAS3) in Madin-Darby canine kidney (MDCK) cells cultured in a 3-D matrix as epithelial cysts released large amounts of HAS- and hyaluronan-positive vesicles from their basal surfaces into the extracellular matrix. Hence, hyaluronan synthesis is one of the first molecular mechanisms to stimulate the production of MVs. ${ }^{133}$ Emam et al exposed four different cell lines, colon 26 (C26) murine colorectal cancer cell line, B16BL6 murine melanoma cell line, MKN45 human gastric cancer cell line, and DLD-1 human colorectal cancer cell line exposed to neutral, cationic-bare, and PEGylated liposomes. Both neutral and cationic bare liposomes enhanced exosome secretion in a dose-dependent manner, and among neutral and cationic liposomes, fluid cationic liposomes exhibited the strongest stimulation. ${ }^{250}$ Hypoxia plays a significant role in cancer progression, angiogenesis, and metastasis through exosome-mediated signaling. To check the effect of hypoxia, King et al exposed three different breast cancer cell lines to moderate $\left(1 \% \mathrm{O}_{2}\right)$ and severe $\left(0.1 \% \mathrm{O}_{2}\right)$ hypoxia conditions. As a result of exposure, the level of exosome secretion and release significantly increased in conditioned media. $^{251}$ Hannafon et al treated MCF7 and MDA-MB -231 breast cancer cells treated with DHA, which increased exosome secretion and exosome microRNA 
content. Interestingly, miRNA-containing exosomes were increased in other breast cancer lines, such as MDA-MB -231, ZR751, and BT20, whereas there was no increase in normal breast cells (MCF10A). ${ }^{252}$ The HDAC6 inhibitor tubacin was used by Caho et al to selectively induce the release of $\mathrm{CD} 133^{+}$EVs from cancer cells. This effect was not observed with another selective HDAC6 inhibitor, ACY-1215, the pan-HDAC inhibitor trichostatin A (TSA), or knockdown of HDAC6. Tubacin-induced $\mathrm{EV}$ release is associated with changes in cellular lipid composition, loss of clonogenic capacity, and decreased ability to form multicellular aggregates. ${ }^{253}$ Liver kinase B1 (LKB1) regulates multicellular functions including cell polarity, energy metabolism, and cell growth by targeting multiple signaling pathways such as AMPK/mTOR and p53. Zhang et al introduced LKB1 into H460 and A549 lung cancer cells that were endogenously deficient in LKB1 expression and enhanced the release of exosomes. $^{254}$ Oxidative stress induces DNA damage, which in turn activates the ceramide synthesis pathway leading to an increase in senescence-associated EV (SAEV) biogenesis. ${ }^{107}$ Latent membrane protein 1 (LMP1) is a viral protein that contributes to the modification of $\mathrm{EV}$ content and remodeling of the tumor microenvironment. LMP1 enhances EV production by utilizing LMP1interacting proteins, including Hrs, Syntenin-1, and the ESCRT-III complex. ${ }^{255}$ Glutamine deprivation induces the release of Rab11-positive exosomes from cancer cells by reducing the growth regulatory Akt/mechanistic target of rapamycin complex 1 (mTORC1) signaling. ${ }^{256}$

\section{Impact of Cellular, Heat, and Oxidative Stress on Biogenesis and Release of EVs}

External factors such as cellular stress (endoplasmic reticulum), heat, and oxidative stress play critical roles in the biogenesis and release of EVs (Figure 6). Cellular stress and damage caused by molecular targeted therapeutic stress, ${ }^{257,258}$ anticancer therapeutic DNA damage stress, or $\mathrm{HSS}^{259,260}$ induce co-release of heat shock proteins and vesicles. Furthermore, tissue damage releases damageassociated molecular patterns (DAMPs). ${ }^{261}$ AtienzarAroca et al demonstrated the involvement of oxidative stress in the release of EVs from retinal pigment epithelial cells. $^{262}$ Oxidative stress induces a higher amount of exosome release than controls, with a higher expression of vascular endothelial growth factor receptor (VEGFR) in the membrane and enclosed an extra cargo of VEGFR mRNA. For example, heat stress induces EV release ${ }^{263}$ through DNA damage and apoptosis associated with decreased cell viability. Heat-stressed cells were more likely to survive a subsequent heat shock, which is an adaptive response and become resistant to hyperthermia therapies. Heat stress induces EV release and stress and generates more soluble NKG2D ligands, aggravating the impairment of the cytotoxic response. ${ }^{264}$ Heat stress facilitated the release of EVs carrying doxorubicin (DOX) into MCF-7 cells. DOX-containing EVs inhibited MCF-7 cell proliferation and induced apoptosis. Severe ER stress induces the release of EVs carrying proinflammatory DAMP molecules from BeWo choriocarcinoma cells. ${ }^{265}$ Oxidative stress induces MV formation by complex processes including $\mathrm{Hb}$ oxidation, band 3 clustering, cytoskeleton reorganization, increase in intracellular calcium concentrations, and other alterations in red blood cell cellular organization. ${ }^{266}$ Microenvironmental stresses such as cytostatic, heat, and oxidative stress induce the release of sEVs in melanoma cells, and melanoma-derived sEVs elicited by oxidative stress increased Ki-67 expression in MSCs; sEVs resulting from cytostatic facilitated melanoma cell migration. ${ }^{267}$ Oxidative stress plays an important role in apoptosis and autophagy in retinal astrocytes. Exosomes released from normal and oxidative stress conditions have differential effects on endothelial cell function. $^{268}$ Recently, we reported that oxidative stress and ceramide pathway plays significant role in biogenesis and release of exosomes. For example, human lung epithelial adenocarcinoma cancer cells (A549) treated with platinum nanoparticles increases exosome release. ${ }^{269}$

\section{EVs Function as Nanotherapeutic Agents}

Recent developments in the field of exosome nanotechnology have provided extraordinary opportunities for the development of exosome-based nanotherapeutics. The unique features of the structure, anatomical composition, and morphological characteristics of exosomes make these attractive as natural nanocarriers and next-generation nanoplatforms. Exosomes serve as superior platforms as nanocarriers for robust delivery because of their transmembrane and membrane-anchored proteins that may enhance endocytosis, thus promoting the delivery of their internal contents. ${ }^{270}$ For example, Sun et $\mathrm{al}^{271}$ developed curcumin-loaded exosomes for enhanced anti- 


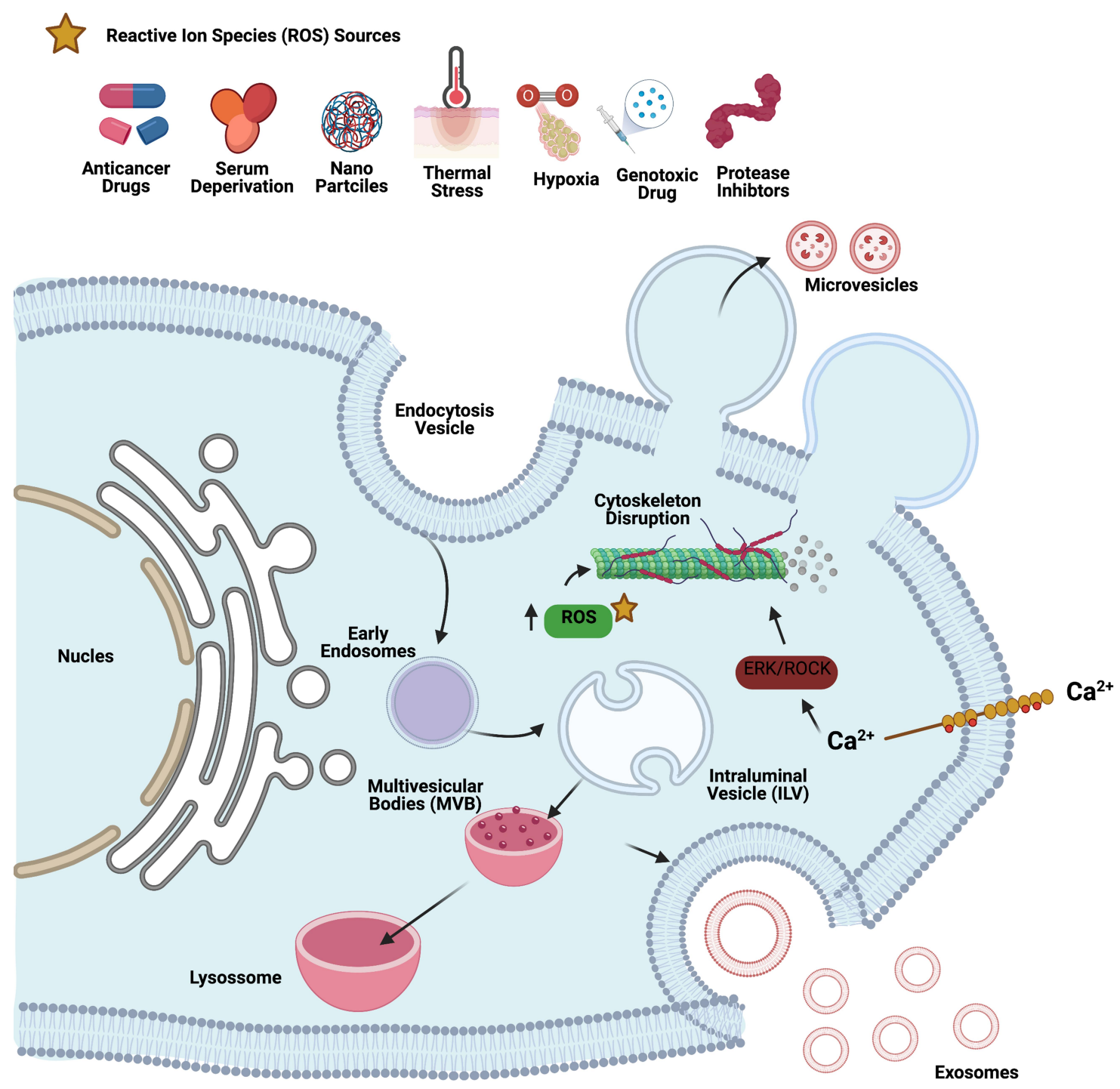

Figure 6 Various sources of oxidative agents responsible for oxidative stress such as anticancer drug, serum deprivation, nanoparticles, thermal stress, hypoxia, genotoxic drugs and protease inhibitors induce biogenesis and release of EVs.

inflammatory activity, and DOX-loaded exosomes have also been used for cancer therapy. ${ }^{272}$ Exosome-based active-targeted cancer therapy was developed using donor cells that were chemically labeled with dual ligands, such as biotin and avidin, on the surface of the cytoplasmic membrane, and then DOX was encapsulated in the cytoplasm. These chemically programmed exosomes displayed high targeting efficiency and desirable therapeutic performance in cancer therapy. ${ }^{273}$ Furthermore, the authors engineered exosome-based nanotherapy with RGD, folic acid (FA), DOX, and gold nanorods for actively targeted chemo/photothermal synergistic cancer therapy. ${ }^{274}$ Exosomes are used as delivery agents for combination therapeutic agents, such as $\mathrm{PH} 20$ hyaluronidase and
DOX, for enhanced tumor penetration and antitumor efficacy. ${ }^{275}$

Nucleic acid components play a significant role in gene therapy. Nucleic acid delivery was first reported for exosome-based nanoplatforms delivery of siRNA to the mouse brain by systemic injection of targeted exosomes. ${ }^{276}$ Exosome-based engineering was used to enable dendritic cells to act as donor cells to express LAMP2B for the treatment of Alzheimer's disease. ${ }^{277,278}$ Bellavia et al developed exosomes loaded with BCR-ABL siRNA that targeted chronic myeloid leukemia cells and inhibited cancer cell growth. ${ }^{277,278}$ Furthermore, these authors developed a combination therapy containing imatinib chemotherapy and siRNAs within exosomes for 
a synergistic approach. ${ }^{278}$ RNA-based nanotechnology plays a significant role in gene therapy. Kojima et $\mathrm{al}^{279}$ reported that new strategic achievements for Parkinson's disease by implanting reprogrammed HEK-293T cells in patients that secreted therapeutic exosomes loaded with biopharmaceutical-encoding mRNAs. These engineered cells have the potential to enhance efficiency, enabling specific mRNA packaging and exosomal mRNA delivery to recipient cells.

These techniques facilitate enhanced therapeutic outcomes and are free from intrinsic limitations in translational research. EVs have been utilized as vehicles for anti-cancer drugs, small RNAs, and anti-inflammatory agents because of their potential ability to cross tissue barriers and deliver their contents to the target cells. The development of EV-based drug delivery systems can enhance the efficacy of drugs by altering their physical and biological properties to reach the target recipient cells and deliver their content. For example, small EVs associated with adeno-associated virus vectors partially rescued hearing in mice by the use of direct cochlear injection with high efficiency and could also cross the blood-brain barrier. ${ }^{280}$ Pathogen-specific antigens containing EVs can be used as tools for the development of new vaccines for infectious diseases in humans and animals. Barbosa et $a^{281}$ reported the potential features of parasitederived EVs that can influence the profile of inflammatory mediators in the intestine of a preclinical mouse model, including cytokines and signaling molecules. EVs secreted by helminths could also promote expression of proinflammatory cytokines. ${ }^{282,283}$

Exosomes are not only carrier molecules for DNA and RNA but can also deliver proteins. Protein-related nanotherapy has attracted much attention owing to the unique specificity of the proteins involved. As a nanoplatform, exosomes contain numerous amounts and varieties of proteins both on the surface and in the inner cytosol providing considerable binding sites for combinations with specific ligands on the surface of recipient cells for targeted therapy or to couple with exogenous therapeutic proteins for efficient protein delivery. ${ }^{39}$ For instance, macrophage-derived exosomes can overcome the blood-brain barrier to treat brain inflammation and also serve as nanocarriers to transfer brain-derived neurotrophic factor for efficient intrabrain delivery of therapeutic proteins. ${ }^{284}$ Exosomes are suitable agents for the delivery of antioxidant agents, such as catalase, which accelerate the degradation of hydrogen peroxide by catalytic reactions and can be used for treatment of Parkinson's disease. ${ }^{285}$ Another group has designed HEK293T-cell-derived exosomes for efficient intracellular optical-responsive protein delivery. ${ }^{286}$

Nanotechnology plays a critical role in immunotherapy, including cancer therapeutic vaccines, for delivery to specific targets without undesired side effects and for production of immunomodulatory effects. In the context of cancer therapy, exosomes facilitate anticancer immunosurveillance and induce immunological rejection against tumors via the expansion of the cytotoxic T lymphocyte repertoire and revitalization of tumor-reactive quiescent T cells. ${ }^{38}$ Dendritic cell-derived exosomes have been shown to suppress the growth of established murine tumors and generate cancer-specific adaptive immune responses for efficient cancer immunotherapy. ${ }^{287}$ MSCderived exosomes induce immunomodulatory effects by increasing cell proliferation and immunomodulation in cancers and help enable tissue regeneration. Nanosystems containing endogenous tumor antigens and immunostimulatory DNA are utilized to enhance cancer immunotherapy, and EVs are used as therapeutic agents in immunotherapy. For instance, EVs from antigen-presenting cells can activate CD4-and CD8-positive T cells through MHC-peptide complexes that enhance immunity to reduce tumor burden in immunocompetent mice. ${ }^{16}$ Acute kidney injury (AKI) is a result of the loss of kidney function, which causes morbidity and mortality. However, there are no definitive therapies for the treatment of AKI. Interleukin-10 (IL-10) is a powerful immune modulator with strong antiinflammatory and tissue regeneration capabilities. ${ }^{288}$ Tang et $\mathrm{al}^{289}$ reported the manufacture of EVs loaded with IL-10 by engineering macrophages for treating ischemic AKI. Exosome-mediated delivery of IL-10 enhanced not only the stability of IL-10, but also targeting to the kidney due to the adhesive components on the EV surface. ${ }^{289} \mathrm{MSC} /$ stromal cell-derived EVs are therapeutically potent against renal ischemia and myocardial reperfusion injury ${ }^{290,291}$ owing to several unique features including immunomodulatory and regenerative aspects. MSC-derived EVs are also protective against toxicantinduced injury. ${ }^{292-294}$ Macrophages stimulated with $\mathrm{CpG}$ oligodeoxynucleotides (ODNs) secreted EVs containing these ODNS that are then used to induce the release of TNF- $\alpha$, which is mainly used for the treatment of autoimmune diseases. ${ }^{295}$ EVs derived from human red blood cells have been utilized as delivery vehicles for EV-based 
gene therapy to deliver antisense oligonucleotides or CAS9 mRNA and gRNAs to cancer cells. ${ }^{296}$

Exosome-based nanoplatforms are potentially used as biomarkers for various types of diseases, including cancer. In particular, tumor-derived exosomes can provide diagnostic information and aid in making therapeutic decisions for patients with cancer through a blood test. For example, molecular characteristics of gliomas such as mRNA mutants/variants, miRNAs, and cancer-specific EGFR vIII were detected in serum exosomes of patients with glioblastoma. ${ }^{297}$ Recently, the mRNA of exosomes from patients with glioblastoma was shown to be easily detectable by using advanced technology, such as microfluidic chip-based analytic approaches. ${ }^{298}$ Cancer cell-derived exosomes contain proteoglycan, glypican-1 (GPC1), and serve as a potential noninvasive diagnostic and screening tool for the early stage of pancreatic cancer detection. ${ }^{299}$ Exosomes secreted from $\mathrm{T}$ lymphocytes have served as surrogate markers of inflammation. ${ }^{300}$ EV-associated molecular cargo such as miRNA repertoire provided useful diagnostic and/or prognostic information for the management of $\mathrm{T}_{2} \mathrm{DM} .^{227} \mathrm{CD} 31^{+}$extracellular vesicles from patients with type 2 diabetes of blood circulating miRNAs signature serving as tool to detect T2DM complications. $^{227}$ Since the last decade, significant progress has been achieved in the field of exosome-based nanomedical applications; however, this field is still in its infancy.

\section{Current Challenges and Perspectives of Extracellular Vesicles from a Clinical Point of View}

EVs are used as drug delivery vehicle for the delivery of siRNAs, miRNAs, protein, small molecule drugs, nanoparticles, and CRISPR/Cas9 in the treatment of various diseases. EVs can easily penetrate into the tissues even into the brain and it can enhance the targetability. EVsbased drug delivery remains challenging, due to lack of standardized isolation and purification methods, limited drug loading efficiency, and insufficient clinical grade production. $^{301}$ EVs-based therapeutics plays significant promise to enable targeted drug delivery with superior efficiency. EVs-based therapy is naturally lipid and surface protein composition, which enable them to evade phagocytosis, extend blood half-life, and reduce long-term safety issues compared with existing liposomes or polymeric nanoparticles. The small size of EVs facilitates their extravasation, translocation through physical barriers, and passage through extracellular matrix. MSC-derived EVs were capable of increasing survival in a mouse model of pancreatic cancer. EVs have significant advantage as natural drug delivery, ${ }^{302,303}$ keep stability, ${ }^{304}$ and maintain sufficient binding effects. ${ }^{305}$ For successful clinical application of EVs, cell-derived therapeutic EVs will need to be manufactured at sufficient levels with high purity as well as they should contain the appropriate cargo and surface molecules to make the exosome an effective medicine for the intended patient. ${ }^{306}$ The downstream processing of EVs should keep necessary quality control for therapeutic purposes.

\section{Conclusion and Future Perspective}

In this review, we presented recent advances in biogenesis, cargo sorting, membrane trafficking, and functions of EVs. Furthermore, we concentrated on the current state of the art in the field of EV-based applications in creating and tailoring theranostic nanomaterials and the importance of EVs as nanotherapeutic agents. Generally, EV biogenesis and secretion are complicated processes involving the involvement of several proteins; however, the exact mechanism of several proteins remains elusive. The rapid development of the field of EV research has led to an understanding of their specific roles in both normal and disease physiology. Further, these mechanistic studies provide a way to understand the mechanisms regulating cargo enrichment and EV release. Mounting evidence suggests that EVs are becoming regarded as an increasingly important mechanism of intercellular communication and as vital components of both basic and clinical studies. Although numerous studies have contributed to the sorting of various proteins, RNAs, and lipids into EVs, a large gap still needs to be addressed on the importance of posttranslational modifications in conferring specific properties to proteins and sorting them into EVs. For instance, the same protein can be modified in different ways by posttranslational modifications because ubiquitination plays a significant role in packaging and secretion. EVs serve as natural carriers of biomolecules because they are nanosized particles, have low immunogenicity, lack cytotoxicity, and have long-term safety.

The next important question that needs to be addressed is whether the MVBs present in ILVs can either fuse with the lysosomes or with the plasma membrane? Whether this is the result of the co-existence of two different 
populations of MVBs inside the cells or the activation of specific signaling pathways is still a subject of investigation; in addition, the dependency of exosome biogenesis on the activity of the whole SNARE complex is unclear. Furthermore, the development of reproducible in vitro assay systems is necessary to study EV cargo loading that closely mimics the physiological context and would be helpful in answering many questions related to the targeting and packaging of EV cargo molecules. To understand the fundamental properties of EV biogenesis, including the role of varying molecular components and changes in membrane topology during EV formation, novel molecular techniques are required that can distinguish EVs from one another once they have entered the extracellular space and also that can differentiate EVs derived from the endocytic pathway from those shed from the plasma membrane. Furthermore, questions also remain concerning the energetic requirements for $\mathrm{EV}$ biogenesis, how various stimuli, including temperature, culture conditions, serum, and stress activators, as well as how the molecular interactions between EVs and cells are influenced by various physical and chemical factors. ${ }^{307}$

Although EVs are utilized in various biomedical applications, currently available methods for isolation, purification, characterization, and upscale processing are timeconsuming, inefficient, and expensive, which hinders further commercialization and clinical translation of exosomes. Therefore, a special consortium is required to regularize the most important criteria, such as the development of new techniques for isolating and studying EVs and their exclusive purification and characterization for theranostic applications of EVs, as well as routes of EV administration and bio-distribution. Owing to the rapid development and usage of EVs, nanotechnology can provide a sound theoretical basis for the isolation, purification, and characterization of EVs for an improved understanding of their specific physicochemical properties such as vesicular size, geometry, surface features, stiffness, chemical composition, and physiologic stability. Using currently available techniques, it is very difficult to distinguish between different EV subtypes. Hence, new techniques are required to differentiate various subtypes of vesicles, such as endosome-derived and plasma membrane-derived vesicles. To overcome this problem, the selection of cell lines, incubation time, serum concentration, $\mathrm{pH}$, temperature, and other parameters must be followed uniformly to avoid any variations. Exploiting advances in nanotechnology could enable EVs to provide multifunctional roles in various biomedical applications; for instance, surface functionalization of EVs with inorganic nanomaterials, could enhance effectiveness and specific tumor targeting in cancer therapy, including the use of photothermal therapy. Therefore, a variety of exosomebased organic-inorganic hybridized nanosystems are required for nanomedical applications. Finally, the use of all omics systems and specific vesicles, EVs, or exosomes can be used as excellent nanoplatforms for precision medicine.

\section{Acknowledgments}

This study was supported by the KU-Research Professor Program of Konkuk University.

\section{Funding}

This work was supported by a grant from the Science Research Center (2015R1A5A1009701) of the National Research Foundation of Korea.

\section{Disclosure}

The authors declare no conflicts of interest for this work.

\section{References}

1. van Niel G, D'Angelo G, Raposo G. Shedding light on the cell biology of extracellular vesicles. Nat Rev Mol Cell Biol. 2018;19(4):213-228. doi:10.1038/nrm.2017.125

2. Mathieu M, Martin-Jaular L, Lavieu G, Théry C. Specificities of secretion and uptake of exosomes and other extracellular vesicles for cell-to-cell communication. Nat Cell Biol. 2019;21(1):9-17. doi:10.1038/s41556-018-0250-9

3. Théry C, Witwer KW, Aikawa E, et al. Minimal information for studies of extracellular vesicles 2018 (MISEV2018): a position statement of the International Society for Extracellular Vesicles and update of the MISEV2014 guidelines. J Extracell Vesicles. 2018;7 (1):1535750. doi:10.1080/20013078.2018.1535750

4. Witwer KW, Théry C. Extracellular vesicles or exosomes? On primacy, precision, and popularity influencing a choice of nomenclature. $J$ Extracell Vesicles. 2019;8(1):1648167. doi:10.1080/ 20013078.2019.1648167

5. Lee C, Mitsialis SA, Aslam M, et al. Exosomes mediate the cytoprotective action of mesenchymal stromal cells on hypoxia-induced pulmonary hypertension. Circulation. 2012;126(22):2601-2611. doi:10.1161/circulationaha.112.114173

6. Buzas EI, György B, Nagy G, Falus A, Gay S. Emerging role of extracellular vesicles in inflammatory diseases. Nat Rev Rheumatol. 2014;10(6):356-364. doi:10.1038/nrrheum.2014.19

7. Povero D, Eguchi A, Li H, et al. Circulating extracellular vesicles with specific proteome and liver microRNAs are potential biomarkers for liver injury in experimental fatty liver disease. PLoS One. 2014;9(12): e113651. doi:10.1371/journal.pone.0113651

8. Rabinowits G, Gerçel-Taylor C, Day JM, Taylor DD, Kloecker GH. Exosomal microRNA: a diagnostic marker for lung cancer. Clin Lung Cancer. 2009;10(1):42-46. doi:10.3816/CLC.2009.n.006 
9. Tan SS, Yin Y, Lee T, et al. Therapeutic MSC exosomes are derived from lipid raft microdomains in the plasma membrane. $J$ Extracell Vesicles. 2013;2. doi:10.3402/jev.v2i0.22614

10. Théry C, Ostrowski M, Segura E. Membrane vesicles as conveyors of immune responses. Nat Rev Immunol. 2009;9 (8):581-593. doi:10.1038/nri2567

11. Abels ER, Breakefield XO. Introduction to extracellular vesicles: biogenesis, RNA cargo selection, content, release, and uptake. Cell Mol Neurobiol. 2016;36(3):301-312. doi:10.1007/s10571016-0366-z

12. Raposo G, Stoorvogel W. Extracellular vesicles: exosomes, microvesicles, and friends. J Cell Biol. 2013;200(4):373-383. doi:10.1083/jcb.201211138

13. Gould SJ, Raposo G. As we wait: coping with an imperfect nomenclature for extracellular vesicles. $J$ Extracell Vesicles. 2013;2(1):20389. doi:10.3402/jev.v2i0.20389

14. Trams EG, Lauter CJ, Salem J Jr, Heine U. Exfoliation of membrane ecto-enzymes in the form of micro-vesicles. Biochim Biophys Acta. 1981;645(1):63-70. doi:10.1016/0005-2736(81) 90512-5

15. Johnstone RM, Adam M, Hammond JR, Orr L, Turbide C. Vesicle formation during reticulocyte maturation. Association of plasma membrane activities with released vesicles (exosomes). $J$ Biol Chem. 1987;262(19):9412-9420. doi:10.1016/S00219258(18)48095-7

16. Raposo G, Nijman HW, Stoorvogel W, et al. B lymphocytes secrete antigen-presenting vesicles. J Exp Med. 1996;183 (3):1161-1172. doi:10.1084/jem.183.3.1161

17. Zitvogel L, Regnault A, Lozier A, et al. Eradication of established murine tumors using a novel cell-free vaccine: dendritic cell-derived exosomes. Nat Med. 1998;4(5):594-600. doi:10.1038/nm0598-594

18. Minciacchi VR, Freeman MR, Di Vizio D. Extracellular vesicles in cancer: exosomes, microvesicles and the emerging role of large oncosomes. Semin Cell Dev Biol. 2015;40:41-51. doi:10.1016/j. semcdb.2015.02.010

19. Denzer K, Kleijmeer MJ, Heijnen HF, Stoorvogel W, Geuze HJ. Exosome: from internal vesicle of the multivesicular body to intercellular signaling device. $J$ Cell Sci. 2000;113(Pt 19):3365-3374. doi:10.1242/jcs.113.19.3365

20. Russell AE, Jun S, Sarkar S, et al. Extracellular vesicles secreted in response to cytokine exposure increase mitochondrial oxygen consumption in recipient cells. Front Cell Neurosci. 2019;13:51. doi:10.3389/fncel.2019.00051

21. Jeppesen DK, Fenix AM, Franklin JL, et al. Reassessment of exosome composition. Cell. 2019;177(2):428-445.e418. doi:10.1016/j.cell.2019.02.029

22. Hsu C, Morohashi Y, Yoshimura S, et al. Regulation of exosome secretion by Rab35 and its GTPase-activating proteins TBC1D10A-C. J Cell Biol. 2010;189(2):223-232. doi:10.1083/ jcb. 200911018

23. Ostrowski M, Carmo NB, Krumeich S, et al. Rab27a and Rab27b control different steps of the exosome secretion pathway. Nat Cell Biol. 2010;12(1):19-30; sup pp 11-13. doi: $10.1038 /$ ncb2000

24. Hoshino D, Kirkbride KC, Costello K, et al. Exosome secretion is enhanced by invadopodia and drives invasive behavior. Cell Rep. 2013;5(5):1159-1168. doi:10.1016/j.celrep.2013.10.050

25. Colombo M, Moita C, van Niel G, et al. Analysis of ESCRT functions in exosome biogenesis, composition and secretion highlights the heterogeneity of extracellular vesicles. J Cell Sci. 2013;126(Pt 24):5553-5565. doi:10.1242/jcs. 128868

26. Sinha S, Hoshino D, Hong NH, et al. Cortactin promotes exosome secretion by controlling branched actin dynamics. J Cell Biol. 2016;214(2):197-213. doi:10.1083/jcb.201601025
27. Lu A, Wawro P, Morgens DW, Portela F, Bassik MC, Pfeffer SR. Genome-wide interrogation of extracellular vesicle biology using barcoded miRNAs. Elife. 2018;7. doi:10.7554/eLife.41460

28. Yeung V, Webber JP, Dunlop EA, et al. Rab35-dependent extracellular nanovesicles are required for induction of tumour supporting stroma. Nanoscale. 2018;10(18):8547-8559. doi:10.1039/ c8nr02417k

29. Graves LE, Ariztia EV, Navari JR, Matzel HJ, Stack MS, Fishman DA. Proinvasive properties of ovarian cancer ascites-derived membrane vesicles. Cancer Res. 2004;64 (19):7045-7049. doi:10.1158/0008-5472.Can-04-1800

30. Kim DK, Kang B, Kim OY, et al. EVpedia: an integrated database of high-throughput data for systemic analyses of extracellular vesicles. J Extracell Vesicles. 2013;2. doi:10.3402/jev.v2i0.20384

31. Savina A, Furlán M, Vidal M, Colombo MI. Exosome release is regulated by a calcium-dependent mechanism in K562 cells. $J$ Biol Chem. 2003;278(22):20083-20090. doi:10.1074/jbc. M301642200

32. Holleman J, Marchese A. The ubiquitin ligase deltex-31 regulates endosomal sorting of the $\mathrm{G}$ protein-coupled receptor CXCR4. $\mathrm{Mol}$ Biol Cell. 2014;25(12):1892-1904. doi:10.1091/mbc.E13-10-0612

33. van Niel G, Charrin S, Simoes S, et al. The tetraspanin CD63 regulates ESCRT-independent and -dependent endosomal sorting during melanogenesis. Dev Cell. 2011;21(4):708-721. doi:10.1016/j.devcel.2011.08.019

34. Muralidharan-Chari V, Clancy J, Plou C, et al. ARF6-regulated shedding of tumor cell-derived plasma membrane microvesicles. Curr Biol. 2009;19(22):1875-1885. doi:10.1016/j.cub.2009.09.059

35. Perez-Hernandez D, Gutiérrez-Vázquez C, Jorge I, et al. The intracellular interactome of tetraspanin-enriched microdomains reveals their function as sorting machineries toward exosomes. $J$ Biol Chem. 2013;288(17):11649-11661. doi:10.1074/jbc. M112.445304

36. Vanni I, Alama A, Grossi F, Dal Bello MG, Coco S. Exosomes: a new horizon in lung cancer. Drug Discov Today. 2017;22 (6):927-936. doi:10.1016/j.drudis.2017.03.004

37. Kadota T, Yoshioka Y, Fujita Y, Kuwano K, Ochiya T. Extracellular vesicles in lung cancer-from bench to bedside. Semin Cell Dev Biol. 2017;67:39-47. doi:10.1016/j. semcdb.2017.03.001

38. Syn NL, Wang L, Chow EK, Lim CT, Goh BC. Exosomes in cancer nanomedicine and immunotherapy: prospects and challenges. Trends Biotechnol. 2017;35(7):665-676. doi:10.1016/j.tibtech.2017.03.004

39. Yang B, Chen Y, Shi J. Exosome biochemistry and advanced nanotechnology for next-generation theranostic platforms. $A d v$ Mater. 2019;31(2):e1802896. doi:10.1002/adma.201802896

40. Zhang H, Freitas D, Kim HS, et al. Identification of distinct nanoparticles and subsets of extracellular vesicles by asymmetric flow field-flow fractionation. Nat Cell Biol. 2018;20(3):332-343. doi:10.1038/s41556-018-0040-4

41. Zhang Q, Higginbotham JN, Jeppesen DK, et al. Transfer of functional cargo in exomeres. Cell Rep. 2019;27(3):940-954. e946. doi:10.1016/j.celrep.2019.01.009

42. Simons M, Raposo G. Exosomes-vesicular carriers for intercellular communication. Curr Opin Cell Biol. 2009;21(4):575-581. doi:10.1016/j.ceb.2009.03.007

43. Balaj L, Lessard R, Dai L, et al. Tumour microvesicles contain retrotransposon elements and amplified oncogene sequences. Nat Commun. 2011;2:180. doi:10.1038/ncomms1180

44. Ashcroft BA, de Sonneville J, Yuana Y, et al. Determination of the size distribution of blood microparticles directly in plasma using atomic force microscopy and microfluidics. Biomed Microdevices. 2012;14(4):641-649. doi:10.1007/s10544-0129642-y 
45. Dalton AJ. Microvesicles and vesicles of multivesicular bodies versus "virus-like" particles. J Natl Cancer Inst. 1975;54 (5):1137-1148. doi:10.1093/jnci/54.5.1137

46. Gabel V, Miglis M, Zeitzer JM. Effect of artificial dawn light on cardiovascular function, alertness, and balance in middle-aged and older adults. Sleep. 2020;43(10). doi:10.1093/sleep/zsaa082

47. Keller S, Ridinger J, Rupp AK, Janssen JW, Altevogt P. Body fluid derived exosomes as a novel template for clinical diagnostics. $J$ Transl Med. 2011;9:86. doi:10.1186/1479-5876-9-86

48. Hata T, Murakami K, Nakatani H, Yamamoto Y, Matsuda T, Aoki N. Isolation of bovine milk-derived microvesicles carrying mRNAs and microRNAs. Biochem Biophys Res Commun. 2010;396(2):528-533. doi:10.1016/j.bbrc.2010.04.135

49. Wiggins R, Glatfelter A, Kshirsagar B, Beals T. Lipid microvesicles and their association with procoagulant activity in urine and glomeruli of rabbits with nephrotoxic nephritis. Lab Invest. 1987;56(3):264-272.

50. Momen-Heravi F, Balaj L, Alian S, et al. Current methods for the isolation of extracellular vesicles. Biol Chem. 2013;394 (10):1253-1262. doi:10.1515/hsz-2013-0141

51. Livshits MA, Khomyakova E, Evtushenko EG, et al. Isolation of exosomes by differential centrifugation: theoretical analysis of a commonly used protocol. Sci Rep. 2015;5:17319. doi:10.1038/ srep 17319

52. Li P, Kaslan M, Lee SH, Yao J, Gao Z. Progress in exosome isolation techniques. Theranostics. 2017;7(3):789-804. doi: $10.7150 /$ thno. 18133

53. Lobb RJ, Becker M, Wen SW, et al. Optimized exosome isolation protocol for cell culture supernatant and human plasma. $J$ Extracell Vesicles. 2015;4:27031. doi:10.3402/jev.v4.27031

54. Koliha N, Wiencek Y, Heider U, et al. A novel multiplex bead-based platform highlights the diversity of extracellular vesicles. J Extracell Vesicles. 2016;5:29975. doi:10.3402/jev.v5.29975

55. Chen C, Skog J, Hsu CH, et al. Microfluidic isolation and transcriptome analysis of serum microvesicles. Lab Chip. 2010;10 (4):505-511. doi:10.1039/b916199f

56. Brennan K, Martin K, FitzGerald SP, et al. A comparison of methods for the isolation and separation of extracellular vesicles from protein and lipid particles in human serum. Sci Rep. 2020;10 (1):1039. doi:10.1038/s41598-020-57497-7

57. Liangsupree T, Multia E, Riekkola ML. Modern isolation and separation techniques for extracellular vesicles. J Chromatogr A. 2021;1636:461773. doi:10.1016/j.chroma.2020.461773

58. Johnstone RM, Mathew A, Mason AB, Teng K. Exosome formation during maturation of mammalian and avian reticulocytes: evidence that exosome release is a major route for externalization of obsolete membrane proteins. J Cell Physiol. 1991;147 (1):27-36. doi:10.1002/jcp.1041470105

59. Février B, Raposo G. Exosomes: endosomal-derived vesicles shipping extracellular messages. Curr Opin Cell Biol. 2004;16 (4):415-421. doi:10.1016/j.ceb.2004.06.003

60. Wolf $P$. The nature and significance of platelet products in human plasma. Br J Haematol. 1967;13(3):269-288. doi:10.1111/j.13652141.1967.tb08741.x

61. Stein JM, Luzio JP. Ectocytosis caused by sublytic autologous complement attack on human neutrophils. The sorting of endogenous plasma-membrane proteins and lipids into shed vesicles. Biochem J. 1991;274(Pt 2):381-386. doi:10.1042/bj2740381

62. Stahl PD, Raposo G. Extracellular vesicles: exosomes and microvesicles, integrators of homeostasis. Physiology (Bethesda). 2019;34(3):169-177. doi:10.1152/physiol.00045.2018

63. Sims PJ, Faioni EM, Wiedmer T, Shattil SJ. Complement proteins C5b-9 cause release of membrane vesicles from the platelet surface that are enriched in the membrane receptor for coagulation factor Va and express prothrombinase activity. J Biol Chem. 1988;263(34):18205-18212.
64. Hessvik NP, Llorente A. Current knowledge on exosome biogenesis and release. Cell Mol Life Sci. 2018;75(2):193-208. doi:10.1007/s00018-017-2595-9

65. D'Souza-Schorey C, Clancy JW. Tumor-derived microvesicles: shedding light on novel microenvironment modulators and prospective cancer biomarkers. Genes Dev. 2012;26(12):1287-1299. doi:10.1101/gad.192351.112

66. Kowal J, Tkach M, Théry C. Biogenesis and secretion of exosomes. Curr Opin Cell Biol. 2014;29:116-125. doi:10.1016/ j.ceb.2014.05.004

67. Keller S, Sanderson MP, Stoeck A, Altevogt P. Exosomes: from biogenesis and secretion to biological function. Immunol Lett. 2006;107(2):102-108. doi:10.1016/j.imlet.2006.09.005

68. Mayor S, Pagano RE. Pathways of clathrin-independent endocytosis. Nat Rev Mol Cell Biol. 2007;8(8):603-612. doi:10.1038/nrm2216

69. Huotari J, Helenius A. Endosome maturation. EMBO j. 2011;30 (17):3481-3500. doi:10.1038/emboj.2011.286

70. Cocucci E, Racchetti G, Meldolesi J. Shedding microvesicles: artefacts no more. Trends Cell Biol. 2009;19(2):43-51. doi:10.1016/j.tcb.2008.11.003

71. Fader CM, Sánchez DG, Mestre MB, Colombo MI. TI-VAMP /VAMP7 and VAMP3/cellubrevin: two v-SNARE proteins involved in specific steps of the autophagy/multivesicular body pathways. Biochim Biophys Acta. 2009;1793(12):1901-1916. doi:10.1016/j.bbamcr.2009.09.011

72. Luzio JP, Gray SR, Bright NA. Endosome-lysosome fusion. Biochem Soc Trans. 2010;38(6):1413-1416. doi:10.1042/ bst0381413

73. Liu C, Su C. Design strategies and application progress of therapeutic exosomes. Theranostics. 2019;9(4):1015-1028. doi: $10.7150 /$ thno. 30853

74. Tai YL, Chen KC, Hsieh JT, Shen TL. Exosomes in cancer development and clinical applications. Cancer Sci. 2018;109 (8):2364-2374. doi:10.1111/cas.13697

75. Gurunathan S, Chapman-Shimshoni D, Trajkovic S, Gerst JE. Yeast exocytic v-SNAREs confer endocytosis. Mol Biol Cell. 2000;11(10):3629-3643. doi:10.1091/mbc.11.10.3629

76. Gurunathan S, David D, Gerst JE. Dynamin and clathrin are required for the biogenesis of a distinct class of secretory vesicles in yeast. EMBO j. 2002;21(4):602-614. doi:10.1093/emboj/ 21.4.602

77. Trajkovic K, Hsu C, Chiantia S, et al. Ceramide triggers budding of exosome vesicles into multivesicular endosomes. Science. 2008;319(5867):1244-1247. doi:10.1126/science.1153124

78. Morvan J, Rinaldi B, Friant S. Pkh1/2-dependent phosphorylation of Vps 27 regulates ESCRT-I recruitment to endosomes. Mol Biol Cell. 2012;23(20):4054-4064. doi:10.1091/mbc.E12-010001

79. Adell MA, Vogel GF, Pakdel M, et al. Coordinated binding of Vps4 to ESCRT-III drives membrane neck constriction during MVB vesicle formation. $J$ Cell Biol. 2014;205(1):33-49. doi:10.1083/jcb.201310114

80. Romancino DP, Paterniti G, Campos Y, et al. Identification and characterization of the nano-sized vesicles released by muscle cells. FEBS Lett. 2013;587(9):1379-1384. doi:10.1016/j. febslet.2013.03.012

81. McGough IJ, Vincent JP. Exosomes in developmental signalling. Development. 2016;143(14):2482-2493. doi:10.1242/dev.126516

82. Baietti MF, Zhang Z, Mortier E, et al. Syndecan-syntenin-ALIX regulates the biogenesis of exosomes. Nat Cell Biol. 2012;14 (7):677-685. doi:10.1038/ncb2502

83. Theos AC, Berson JF, Theos SC, et al. Dual loss of ER export and endocytic signals with altered melanosome morphology in the silver mutation of Pmel17. Mol Biol Cell. 2006;17 (8):3598-3612. doi:10.1091/mbc.e06-01-0081 
84. Kajimoto T, Okada T, Miya S, Zhang L, Nakamura S. Ongoing activation of sphingosine 1-phosphate receptors mediates maturation of exosomal multivesicular endosomes. Nat Commun. 2013;4:2712. doi:10.1038/ncomms3712

85. Yu X, Harris SL, Levine AJ. The regulation of exosome secretion: a novel function of the p53 protein. Cancer Res. 2006;66 (9):4795-4801. doi:10.1158/0008-5472.Can-05-4579

86. Wang Y, Balaji V, Kaniyappan S, et al. The release and trans-synaptic transmission of Tau via exosomes. Mol Neurodegener. 2017;12(1):5. doi:10.1186/s13024-016-0143-y

87. Marsh AA, Finger EC, Mitchell DG, et al. Reduced amygdala response to fearful expressions in children and adolescents with callous-unemotional traits and disruptive behavior disorders. $\mathrm{Am}$ $J \quad$ Psychiatry. 2008;165(6):712-720. doi:10.1176/appi. ajp.2007.07071145

88. Kobayashi H, Tanaka N, Asao H, et al. Hrs, a mammalian master molecule in vesicular transport and protein sorting, suppresses the degradation of ESCRT proteins signal transducing adaptor molecule 1 and 2. J Biol Chem. 2005;280(11):10468-10477. doi:10.1074/jbc.M409969200

89. van Niel G, Porto-Carreiro I, Simoes S, Raposo G. Exosomes: a common pathway for a specialized function. $J$ Biochem. 2006;140(1):13-21. doi: $10.1093 / \mathrm{jb} / \mathrm{mvj} 128$

90. Ren X, Hurley JH. VHS domains of ESCRT-0 cooperate in high-avidity binding to polyubiquitinated cargo. EMBO $\mathrm{j}$. 2010;29(6):1045-1054. doi:10.1038/emboj.2010.6

91. Wollert T, Wunder C, Lippincott-Schwartz J, Hurley JH. Membrane scission by the ESCRT-III complex. Nature. 2009;458(7235):172-177. doi:10.1038/nature07836

92. Yeates EF, Tesco G. The endosome-associated deubiquitinating enzyme USP8 regulates BACE1 enzyme ubiquitination and degradation. $J$ Biol Chem. 2016;291(30):15753-15766. doi: $10.1074 /$ jbc.M116.718023

93. Laulagnier K, Motta C, Hamdi S, et al. Mast cell- and dendritic cell-derived exosomes display a specific lipid composition and an unusual membrane organization. Biochem J. 2004;380(Pt 1):161-171. doi:10.1042/bj20031594

94. Ghossoub R, Lembo F, Rubio A, et al. Syntenin-ALIX exosome biogenesis and budding into multivesicular bodies are controlled by ARF6 and PLD2. Nat Commun. 2014;5:3477. doi:10.1038/ ncomms 4477

95. Stenmark H. Rab GTPases as coordinators of vesicle traffic. Nat Rev Mol Cell Biol. 2009;10(8):513-525. doi:10.1038/nrm2728

96. Tauro BJ, Mathias RA, Greening DW, et al. Oncogenic H-ras reprograms Madin-Darby canine kidney (MDCK) cell-derived exosomal proteins following epithelial-mesenchymal transition. Mol Cell Proteomics. 2013;12(8):2148-2159. doi:10.1074/mcp. M112.027086

97. Savina A, Vidal M, Colombo MI. The exosome pathway in K562 cells is regulated by Rab11. J Cell Sci. 2002;115(Pt 12):2505-2515.

98. Savina A, Fader CM, Damiani MT, Colombo MI. Rab11 promotes docking and fusion of multivesicular bodies in a calcium-dependent manner. Traffic. 2005;6(2):131-143. doi:10.1111/j.1600-0854.2004.00257.x

99. Bobrie A, Krumeich S, Reyal F, et al. Rab27a supports exosome-dependent and -independent mechanisms that modify the tumor microenvironment and can promote tumor progression. Cancer Res. 2012;72(19):4920-4930. doi:10.1158/ 0008-5472.Can-12-0925

100. Zomer A, Vendrig T, Hopmans ES, van Eijndhoven M, Middeldorp JM, Pegtel DM. Exosomes: fit to deliver small RNA. Commun Integr Biol. 2010;3(5):447-450. doi:10.4161/ cib.3.5.12339
101. Choi DS, Yang JS, Choi EJ, et al. The protein interaction network of extracellular vesicles derived from human colorectal cancer cells. J Proteome Res. 2012;11(2):1144-1151. doi:10.1021/pr200842h

102. Li J, Lee Y, Johansson HJ, et al. Serum-free culture alters the quantity and protein composition of neuroblastoma-derived extracellular vesicles. J Extracell Vesicles. 2015;4:26883. doi:10.3402/ jev.v4.26883

103. Setti M, Osti D, Richichi C, et al. Extracellular vesicle-mediated transfer of CLIC1 protein is a novel mechanism for the regulation of glioblastoma growth. Oncotarget. 2015;6(31):31413-31427. doi:10.18632/oncotarget.5105

104. Yang Q, Nanayakkara GK, Drummer C, et al. Low-intensity ultrasound-induced anti-inflammatory effects are mediated by several new mechanisms including gene induction, immunosuppressor cell promotion, and enhancement of exosome biogenesis and docking. Front Physiol. 2017;8:818. doi:10.3389/ fphys.2017.00818

105. Tang X, Chang C, Guo J, et al. Tumour-secreted Hsp90 $\alpha$ on external surface of exosomes mediates tumour - stromal cell communication via autocrine and paracrine mechanisms. Sci Rep. 2019;9(1):15108. doi:10.1038/s41598-019-51704-w

106. Giordano C, Gelsomino L, Barone I, et al. Leptin modulates exosome biogenesis in breast cancer cells: an additional mechanism in cell-to-cell communication. J Clin Med. 2019;8(7):1027. doi: $10.3390 /$ jem 8071027

107. Hitomi K, Okada R, Loo TM, Miyata K, Nakamura AJ, Takahashi A. DNA damage regulates senescence-associated extracellular vesicle release via the ceramide pathway to prevent excessive inflammatory responses. Int $J$ Mol Sci. 2020;21 (10):3720. doi:10.3390/ijms21103720

108. Hanahan D, Weinberg RA. Hallmarks of cancer: the next generation. Cell. 2011;144(5):646-674. doi:10.1016/j. cell.2011.02.013

109. Roma-Rodrigues C, Raposo LR, Cabral R, Paradinha F, Baptista PV, Fernandes AR. Tumor microenvironment modulation via gold nanoparticles targeting malicious exosomes: implications for cancer diagnostics and therapy. Int J Mol Sci. 2017;18 (1):162. doi:10.3390/ijms18010162

110. Gurunathan S, Kang MH, Kim JH. A comprehensive review on factors influences biogenesis, functions, therapeutic and clinical implications of exosomes. Int $J$ Nanomedicine. 2021;16:1281-1312. doi:10.2147/ijn.S291956

111. Zhang Y, Liu Y, Liu H, Tang WH. Exosomes: biogenesis, biologic function and clinical potential. Cell Biosci. 2019;9:19. doi:10.1186/s13578-019-0282-2

112. Tricarico C, Clancy J, D'Souza-Schorey C. Biology and biogenesis of shed microvesicles. Small GTPases. 2017;8(4):220-232. doi:10.1080/21541248.2016.1215283

113. Clancy JW, Sedgwick A, Rosse C, et al. Regulated delivery of molecular cargo to invasive tumour-derived microvesicles. Nat Commun. 2015;6:6919. doi:10.1038/ncomms7919

114. Sedgwick AE, Clancy JW, Olivia Balmert M, D'Souza-Schorey C. Extracellular microvesicles and invadopodia mediate non-overlapping modes of tumor cell invasion. Sci Rep. 2015;5:14748. doi: $10.1038 /$ srep 14748

115. Kozlov MM, Campelo F, Liska N, Chernomordik LV, Marrink SJ, McMahon HT. Mechanisms shaping cell membranes. Curr Opin Cell Biol. 2014;29:53-60. doi:10.1016/j.ceb.2014.03.006

116. McMahon HT, Boucrot E. Membrane curvature at a glance. $J$ Cell Sci. 2015;128(6):1065-1070. doi:10.1242/jcs.114454

117. Li B, Antonyak MA, Zhang J, Cerione RA. RhoA triggers a specific signaling pathway that generates transforming microvesicles in cancer cells. Oncogene. 2012;31(45):4740-4749. doi:10.1038/onc.2011.636 
118. Gulei D, Irimie AI, Cojocneanu-Petric R, Schultze JL, BerindanNeagoe I. Exosomes-small players, big sound. Bioconjug Chem. 2018;29(3):635-648. doi:10.1021/acs.bioconjchem.8b00003

119. Christ L, Wenzel EM, Liestøl K, Raiborg C, Campsteijn C, Stenmark H. ALIX and ESCRT-I/II function as parallel ESCRT-III recruiters in cytokinetic abscission. $J$ Cell Biol. 2016;212(5):499-513. doi:10.1083/jcb.201507009

120. Sedgwick AE, D'Souza-Schorey C. The biology of extracellular microvesicles. Traffic. 2018;19(5):319-327. doi:10.1111/ tra. 12558

121. Crawford S, Diamond D, Brustolon L, Penarreta R. Effect of increased extracellular ca on microvesicle production and tumor spheroid formation. Cancer Microenviron. 2010;4(1):93-103. doi:10.1007/s12307-010-0049-0

122. Monteith GR, Prevarskaya N, Roberts-Thomson SJ. The calcium-cancer signalling nexus. Nat Rev Cancer. 2017;17 (6):367-380. doi:10.1038/nrc.2017.18

123. Bucki R, Bachelot-Loza C, Zachowski A, Giraud F, Sulpice JC. Calcium induces phospholipid redistribution and microvesicle release in human erythrocyte membranes by independent pathways. Biochemistry. 1998;37(44):15383-15391. doi:10.1021/ bi9805238

124. Burnett LA, Light MM, Mehrotra P, Nowak RA. Stimulation of GPR30 increases release of EMMPRIN-containing microvesicles in human uterine epithelial cells. J Clin Endocrinol Metab. 2012;97(12):4613-4622. doi:10.1210/jc.2012-2098

125. Del Conde I, Shrimpton CN, Thiagarajan P, López JA. Tissuefactor-bearing microvesicles arise from lipid rafts and fuse with activated platelets to initiate coagulation. Blood. 2005;106 (5):1604-1611. doi:10.1182/blood-2004-03-1095

126. Budnik V, Ruiz-Cañada C, Wendler F. Extracellular vesicles round off communication in the nervous system. Nat Rev Neurosci. 2016;17(3):160-172. doi:10.1038/nrn.2015.29

127. Wang T, Gilkes DM, Takano N, et al. Hypoxia-inducible factors and RAB22A mediate formation of microvesicles that stimulate breast cancer invasion and metastasis. Proc Natl Acad Sci U S A. 2014;111(31):E3234-3242. doi:10.1073/pnas.1410041111

128. Di Vizio D, Morello M, Dudley AC, et al. Large oncosomes in human prostate cancer tissues and in the circulation of mice with metastatic disease. Am J Pathol. 2012;181(5):1573-1584. doi:10.1016/j.ajpath.2012.07.030

129. Di Vizio D, Kim J, Hager MH, et al. Oncosome formation in prostate cancer: association with a region of frequent chromosomal deletion in metastatic disease. Cancer Res. 2009;69 (13):5601-5609. doi:10.1158/0008-5472.Can-08-3860

130. Stachowiak JC, Schmid EM, Ryan CJ, et al. Membrane bending by protein-protein crowding. Nat Cell Biol. 2012;14(9):944-949. doi:10.1038/ncb2561

131. Yang JS, Gad H, Lee SY, et al. A role for phosphatidic acid in COPI vesicle fission yields insights into Golgi maintenance. Nat Cell Biol. 2008;10(10):1146-1153. doi:10.1038/ncb1774

132. McConnell RE, Higginbotham JN, Shifrin DA Jr, Tabb DL, Coffey RJ, Tyska MJ. The enterocyte microvillus is a vesicle-generating organelle. $J$ Cell Biol. 2009;185 (7):1285-1298. doi:10.1083/jcb.200902147

133. Rilla K, Pasonen-Seppänen S, Deen AJ, et al. Hyaluronan production enhances shedding of plasma membrane-derived microvesicles. Exp Cell Res. 2013;319(13):2006-2018. doi:10.1016/j.yexcr.2013.05.021

134. Choi DS, Lee JM, Park GW, et al. Proteomic analysis of microvesicles derived from human colorectal cancer cells. J Proteome Res. 2007;6(12):4646-4655. doi:10.1021/pr070192y

135. Xu Y, Zhang Y, Wang L, et al. miR-200a targets Gelsolin: a novel mechanism regulating secretion of microvesicles in hepatocellular carcinoma cells. Oncol Rep. 2017;37(5):2711-2719. doi:10.3892/ or.2017.5506
136. Taylor J, Azimi I, Monteith G, Bebawy M. $\mathrm{Ca}(2+)$ mediates extracellular vesicle biogenesis through alternate pathways in malignancy. $J$ Extracell Vesicles. 2020;9(1):1734326. doi:10.1080/20013078.2020.1734326

137. Akers JC, Gonda D, Kim R, Carter BS, Chen CC. Biogenesis of extracellular vesicles (EV): exosomes, microvesicles, retrovirus-like vesicles, and apoptotic bodies. $J$ Neurooncol. 2013;113(1):1-11. doi:10.1007/s11060-013-1084-8

138. Caruso S, Poon IKH. Apoptotic cell-derived extracellular vesicles: more than just debris. Front Immunol. 2018;9:1486. doi:10.3389/fimmu.2018.01486

139. Brock CK, Wallin ST, Ruiz OE, et al. Stem cell proliferation is induced by apoptotic bodies from dying cells during epithelial tissue maintenance. Nat Commun. 2019;10(1):1044. doi:10.1038/ s41467-019-09010-6

140. Collino F, Bruno S, Incarnato D, et al. AKI recovery induced by mesenchymal stromal cell-derived extracellular vesicles carrying microRNAs. $J$ Am Soc Nephrol. 2015;26(10):2349-2360. doi:10.1681/asn.2014070710

141. Depraetere V. "Eat me" signals of apoptotic bodies. Nat Cell Biol. 2000;2(6):E104. doi:10.1038/35014098

142. Gardai SJ, McPhillips KA, Frasch SC, et al. Cell-surface calreticulin initiates clearance of viable or apoptotic cells through trans-activation of LRP on the phagocyte. Cell. 2005;123 (2):321-334. doi:10.1016/j.cell.2005.08.032

143. Orlando KA, Stone NL, Pittman RN. Rho kinase regulates fragmentation and phagocytosis of apoptotic cells. Exp Cell Res. 2006;312(1):5-15. doi:10.1016/j.yexcr.2005.09.012

144. Atkin-Smith GK, Tixeira R, Paone S, et al. A novel mechanism of generating extracellular vesicles during apoptosis via a beads-ona-string membrane structure. Nat Commun. 2015;6:7439. doi:10.1038/ncomms8439

145. Núñez R, Sancho-Martínez SM, Novoa JM, López-Hernández FJ. Apoptotic volume decrease as a geometric determinant for cell dismantling into apoptotic bodies. Cell Death Differ. 2010;17 (11):1665-1671. doi:10.1038/cdd.2010.96

146. Maeno E, Tsubata T, Okada Y. Apoptotic volume decrease (AVD) is independent of mitochondrial dysfunction and initiator caspase activation. Cells. 2012;1(4):1156-1167. doi:10.3390/ cells 1041156

147. Ernest NJ, Habela CW, Sontheimer H. Cytoplasmic condensation is both necessary and sufficient to induce apoptotic cell death. J Cell Sci. 2008;121(Pt 3):290-297. doi:10.1242/ jcs. 017343

148. Crescitelli R, Lässer C, Szabó TG, et al. Distinct RNA profiles in subpopulations of extracellular vesicles: apoptotic bodies, microvesicles and exosomes. J Extracell Vesicles. 2013;2(1):20677. doi:10.3402/jev.v2i0.20677

149. Gregory CD, Dransfield I. Apoptotic tumor cell-derived extracellular vesicles as important regulators of the onco-regenerative niche. Front Immunol. 2018;9:1111. doi:10.3389/ fimmu.2018.01111

150. Hauser P, Wang S, Didenko VV. Apoptotic bodies: selective detection in extracellular vesicles. Methods Mol Biol. 2017;1554:193-200. doi:10.1007/978-1-4939-6759-9_12

151. Lunavat TR, Cheng L, Kim DK, et al. Small RNA deep sequencing discriminates subsets of extracellular vesicles released by melanoma cells-evidence of unique microRNA cargos. RNA Biol. 2015;12(8):810-823. doi:10.1080/15476286.2015.1056975

152. Meldolesi J. Exosomes and ectosomes in intercellular communication. Curr Biol. 2018;28(8):R435-r444. doi:10.1016/ j.cub.2018.01.059

153. Colombo M, Raposo G, Théry C. Biogenesis, secretion, and intercellular interactions of exosomes and other extracellular vesicles. Annu Rev Cell Dev Biol. 2014;30:255-289. doi:10.1146/annurev-cellbio-101512-122326 
154. Cocucci E, Meldolesi J. Ectosomes and exosomes: shedding the confusion between extracellular vesicles. Trends Cell Biol. 2015;25(6):364-372. doi:10.1016/j.tcb.2015.01.004

155. Palmisano G, Jensen SS, Le Bihan MC, et al. Characterization of membrane-shed microvesicles from cytokine-stimulated $\beta$-cells using proteomics strategies. Mol Cell Proteomics. 2012;11 (8):230-243. doi:10.1074/mcp.M111.012732

156. Dinkla S, van Cranenbroek B, van der Heijden WA, et al. Platelet microparticles inhibit IL-17 production by regulatory $\mathrm{T}$ cells through P-selectin. Blood. 2016;127(16):1976-1986. doi:10.1182/blood-2015-04-640300

157. Al-Nedawi K, Meehan B, Micallef J, et al. Intercellular transfer of the oncogenic receptor EGFRvIII by microvesicles derived from tumour cells. Nat Cell Biol. 2008;10(5):619-624. doi:10.1038/ ncb1725

158. Meehan B, Rak J, Di Vizio D. Oncosomes - large and small: what are they, where they came from? $J$ Extracell Vesicles. 2016;5:33109. doi:10.3402/jev.v5.33109

159. Clancy JW, Zhang Y, Sheehan C, D'Souza-Schorey C. An ARF6-Exportin-5 axis delivers pre-miRNA cargo to tumour microvesicles. Nat Cell Biol. 2019;21(7):856-866. doi:10.1038/ s41556-019-0345-y

160. Pasquet JM, Dachary-Prigent J, Nurden AT. Calcium influx is a determining factor of calpain activation and microparticle formation in platelets. Eur $J$ Biochem. 1996;239(3):647-654. doi:10.1111/j.1432-1033.1996.0647u.x

161. Minciacchi VR, You S, Spinelli C, et al. Large oncosomes contain distinct protein cargo and represent a separate functional class of tumor-derived extracellular vesicles. Oncotarget. 2015;6 (13):11327-11341. doi:10.18632/oncotarget.3598

162. Bertolini I, Terrasi A, Martelli C, et al. A GBM-like V-ATPase signature directs cell-cell tumor signaling and reprogramming via large oncosomes. EBioMedicine. 2019;41:225-235. doi:10.1016/ j.ebiom.2019.01.051

163. Morello M, Minciacchi VR, de Candia P, et al. Large oncosomes mediate intercellular transfer of functional microRNA. Cell Cycle. 2013;12(22):3526-3536. doi:10.4161/cc.26539

164. Ciardiello C, Cavallini L, Spinelli C, et al. Focus on extracellular vesicles: new frontiers of cell-to-cell communication in cancer. Int J Mol Sci. 2016;17(2):175. doi:10.3390/ijms17020175

165. Willms E, Cabañas C, Mäger I, Wood MJA, Vader P. Extracellular vesicle heterogeneity: subpopulations, isolation techniques, and diverse functions in cancer progression. Front Immunol. 2018;9:738. doi:10.3389/fimmu.2018.00738

166. Atay S, Wilkey DW, Milhem M, Merchant M, Godwin AK. Insights into the proteome of gastrointestinal stromal tumors-derived exosomes reveals new potential diagnostic biomarkers. Mol Cell Proteomics. 2018;17(3):495-515. doi:10.1074/mcp.RA117.000267

167. Ciardiello C, Leone A, Lanuti P, et al. Large oncosomes overexpressing integrin alpha-V promote prostate cancer adhesion and invasion via AKT activation. J Exp Clin Cancer Res. 2019;38 (1):317. doi:10.1186/s13046-019-1317-6

168. Parolini I, Federici C, Raggi C, et al. Microenvironmental $\mathrm{pH}$ is a key factor for exosome traffic in tumor cells. $J$ Biol Chem. 2009;284(49):34211-34222. doi:10.1074/jbc.M109.041152

169. Montecalvo A, Larregina AT, Shufesky WJ, et al. Mechanism of transfer of functional microRNAs between mouse dendritic cells via exosomes. Blood. 2012;119(3):756-766. doi:10.1182/blood2011-02-338004

170. Heusermann W, Hean J, Trojer D, et al. Exosomes surf on filopodia to enter cells at endocytic hot spots, traffic within endosomes, and are targeted to the ER. J Cell Biol. 2016;213 (2):173-184. doi:10.1083/jcb.201506084
171. Yao Z, Qiao Y, Li X, et al. Exosomes exploit the virus entry machinery and pathway to transmit alpha interferon-induced antiviral activity. J Virol. 2018;92(24). doi:10.1128/jvi.01578-18

172. Théry C, Regnault A, Garin J, et al. Molecular characterization of dendritic cell-derived exosomes. Selective accumulation of the heat shock protein hsc73. J Cell Biol. 1999;147(3):599-610. doi:10.1083/jcb.147.3.599

173. Zaborowski MP, Balaj L, Breakefield XO, Lai CP. Extracellular vesicles: composition, biological relevance, and methods of study. Bioscience. 2015;65(8):783-797. doi:10.1093/biosci/biv084

174. Kalra H, Drummen GP, Mathivanan S. Focus on extracellular vesicles: introducing the next small big thing. Int $J$ Mol Sci. 2016;17(2):170. doi:10.3390/ijms17020170

175. Ragusa M, Barbagallo C, Cirnigliaro M, et al. Asymmetric RNA distribution among cells and their secreted exosomes: biomedical meaning and considerations on diagnostic applications. Front $\mathrm{Mol}$ Biosci. 2017;4:66. doi:10.3389/fmolb.2017.00066

176. Shimoda M, Khokha R. Metalloproteinases in extracellular vesicles. Biochim Biophys Acta Mol Cell Res. 2017;1864 (11):1989-2000. doi:10.1016/j.bbamcr.2017.05.027

177. Batista BS, Eng WS, Pilobello KT, Hendricks-Muñoz KD, Mahal LK. Identification of a conserved glycan signature for microvesicles. J Proteome Res. 2011;10(10):4624-4633. doi:10.1021/pr200434y

178. Janas T, Janas MM, Sapoń K, Janas T. Mechanisms of RNA loading into exosomes. FEBS Lett. 2015;589(13):1391-1398. doi:10.1016/j.febslet.2015.04.036

179. Gibbings DJ, Ciaudo C, Erhardt M, Voinnet O. Multivesicular bodies associate with components of miRNA effector complexes and modulate miRNA activity. Nat Cell Biol. 2009;11 (9):1143-1149. doi:10.1038/ncb1929

180. Katzmann DJ, Babst M, Emr SD. Ubiquitin-dependent sorting into the multivesicular body pathway requires the function of a conserved endosomal protein sorting complex, ESCRT-I. Cell. 2001;106(2):145-155. doi:10.1016/s0092-8674(01)00434-2

181. Gillooly DJ, Raiborg C, Stenmark H. Phosphatidylinositol 3-phosphate is found in microdomains of early endosomes. Histochem Cell Biol. 2003;120(6):445-453. doi:10.1007/s00418003-0591-7

182. Villarroya-Beltri C, Baixauli F, Gutiérrez-Vázquez C, SánchezMadrid F, Mittelbrunn M. Sorting it out: regulation of exosome loading. Semin Cancer Biol. 2014;28:3-13. doi:10.1016/j. semcancer.2014.04.009

183. Norris A, Tammineni P, Wang S, et al. SNX-1 and RME-8 oppose the assembly of HGRS-1/ESCRT-0 degradative microdomains on endosomes. Proc Natl Acad Sci U S A. 2017;114(3):E307-e316. doi:10.1073/pnas.1612730114

184. Teo H, Perisic O, González B, Williams RL. ESCRT-II, an endosome-associated complex required for protein sorting: crystal structure and interactions with ESCRT-III and membranes. Dev Cell. 2004;7(4):559-569. doi:10.1016/j.devcel.2004.09.003

185. Frankel EB, Audhya A. ESCRT-dependent cargo sorting at multivesicular endosomes. Semin Cell Dev Biol. 2018;74:4-10. doi:10.1016/j.semcdb.2017.08.020

186. Agromayor M, Martin-Serrano J. Interaction of AMSH with ESCRT-III and deubiquitination of endosomal cargo. $J$ Biol Chem. 2006;281(32):23083-23091. doi:10.1074/jbc.M513803200

187. Sun S, Zhou X, Corvera J, Gallick GE, Lin SH, Kuang J. ALG-2 activates the MVB sorting function of ALIX through relieving its intramolecular interaction. Cell Discov. 2015;1:15018. doi:10.1038/celldisc. 2015.18

188. Dores MR, Chen B, Lin H, et al. ALIX binds a YPX(3)L motif of the GPCR PAR1 and mediates ubiquitin-independent ESCRT-III/ MVB sorting. J Cell Biol. 2012;197(3):407-419. doi:10.1083/ jcb.201110031 
189. Iavello A, Frech VS, Gai C, Deregibus MC, Quesenberry PJ, Camussi G. Role of Alix in miRNA packaging during extracellular vesicle biogenesis. Int $J$ Mol Med. 2016;37(4):958-966. doi:10.3892/ijmm.2016.2488

190. Friand V, David G, Zimmermann P. Syntenin and syndecan in the biogenesis of exosomes. Biol Cell. 2015;107(10):331-341. doi: 10.1111/boc. 201500010

191. Roucourt B, Meeussen S, Bao J, Zimmermann P, David G. Heparanase activates the syndecan-syntenin-ALIX exosome pathway. Cell Res. 2015;25(4):412-428. doi:10.1038/cr.2015.29

192. Stuffers S, Sem Wegner C, Stenmark H, Brech A. Multivesicular endosome biogenesis in the absence of ESCRTs. Traffic. 2009;10 (7):925-937. doi:10.1111/j.1600-0854.2009.00920.x

193. Edgar JR, Eden ER, Futter CE. Hrs- and CD63-dependent competing mechanisms make different sized endosomal intraluminal vesicles. Traffic. 2014;15(2):197-211. doi:10.1111/tra.12139

194. Villarroya-Beltri C, Baixauli F, Mittelbrunn M, et al. ISGylation controls exosome secretion by promoting lysosomal degradation of MVB proteins. Nat Commun. 2016;7:13588. doi:10.1038/ ncomms 13588

195. Ageta H, Ageta-Ishihara N, Hitachi K, et al. UBL3 modification influences protein sorting to small extracellular vesicles. Nat Commun. 2018;9(1):3936. doi:10.1038/s41467-018-06197-y

196. Nabhan JF, Hu R, Oh RS, Cohen SN, Lu Q. Formation and release of arrestin domain-containing protein 1-mediated microvesicles (ARMMs) at plasma membrane by recruitment of TSG101 protein. Proc Natl Acad Sci U S A. 2012;109 (11):4146-4151. doi:10.1073/pnas.1200448109

197. Boukouris S, Mathivanan S. Exosomes in bodily fluids are a highly stable resource of disease biomarkers. Proteomics Clin Appl. 2015;9(3-4):358-367. doi:10.1002/prca.201400114

198. Bobrie A, Colombo M, Krumeich S, Raposo G, Théry C. Diverse subpopulations of vesicles secreted by different intracellular mechanisms are present in exosome preparations obtained by differential ultracentrifugation. $J$ Extracell Vesicles. 2012;1 (1):18397. doi:10.3402/jev.v1i0.18397

199. Schmidt O, Teis D. The ESCRT machinery. Curr Biol. 2012;22 (4):R116-120. doi:10.1016/j.cub.2012.01.028

200. Moreno-Gonzalo J, Osoro K, García U, et al. Anthelmintic effect of heather in goats experimentally infected with Trichostrongylus colubriformis. Parasitol Res. 2014;113(2):693-699. doi:10.1007/ s00436-013-3697-4

201. Stoorvogel W. Resolving sorting mechanisms into exosomes. Cell Res. 2015;25(5):531-532. doi:10.1038/cr.2015.39

202. Putz U, Howitt J, Lackovic J, et al. Nedd4 family-interacting protein 1 (Ndfip1) is required for the exosomal secretion of Nedd4 family proteins. $J$ Biol Chem. 2008;283 (47):32621-32627. doi:10.1074/jbc.M804120200

203. Mackenzie K, Foot NJ, Anand S, et al. Regulation of the divalent metal ion transporter via membrane budding. Cell Discov. 2016;2:16011. doi:10.1038/celldisc.2016.11

204. Anand S, Samuel M, Kumar S, Mathivanan S. Ticket to a bubble ride: cargo sorting into exosomes and extracellular vesicles. Biochim Biophys Acta Proteins Proteom. 2019;1867(12):140203. doi:10.1016/j.bbapap.2019.02.005

205. Kim BY, Olzmann JA, Barsh GS, Chin LS, Li L. Spongiform neurodegeneration-associated E3 ligase Mahogunin ubiquitylates TSG101 and regulates endosomal trafficking. Mol Biol Cell. 2007;18(4):1129-1142. doi:10.1091/mbc.e06-09-0787

206. McDonald B, Martin-Serrano J. No strings attached: the ESCRT machinery in viral budding and cytokinesis. J Cell Sci. 2009;122 (Pt 13):2167-2177. doi:10.1242/jcs.028308

207. Stringer DK, Piper RC. A single ubiquitin is sufficient for cargo protein entry into MVBs in the absence of ESCRT ubiquitination. J Cell Biol. 2011;192(2):229-242. doi:10.1083/ jcb. 201008121
208. Moreno-Gonzalo O, Fernandez-Delgado I, Sanchez-Madrid F. Post-translational add-ons mark the path in exosomal protein sorting. Cell Mol Life Sci. 2018;75(1):1-19. doi:10.1007/ s00018-017-2690-y

209. Hu W, Liu C, Bi ZY, et al. Comprehensive landscape of extracellular vesicle-derived RNAs in cancer initiation, progression, metastasis and cancer immunology. Mol Cancer. 2020;19(1):102. doi:10.1186/s12943-020-01199-1

210. Koppers-Lalic D, Hackenberg M, Bijnsdorp IV, et al. Nontemplated nucleotide additions distinguish the small RNA composition in cells from exosomes. Cell Rep. 2014;8 (6):1649-1658. doi:10.1016/j.celrep.2014.08.027

211. Hinger SA, Cha DJ, Franklin JL, et al. Diverse long RNAs are differentially sorted into extracellular vesicles secreted by colorectal cancer cells. Cell Rep. 2018;25(3):715-725.e714. doi:10.1016/j.celrep.2018.09.054

212. Squadrito ML, Baer C, Burdet F, et al. Endogenous RNAs modulate microRNA sorting to exosomes and transfer to acceptor cells. Cell Rep. 2014;8(5):1432-1446. doi:10.1016/j. celrep.2014.07.035

213. Guduric-Fuchs J, O'Connor A, Camp B, O'Neill CL, Medina RJ, Simpson DA. Selective extracellular vesicle-mediated export of an overlapping set of microRNAs from multiple cell types. BMC Genomics. 2012;13:357. doi:10.1186/1471-2164-13-357

214. McKenzie AJ, Hoshino D, Hong NH, et al. KRAS-MEK signaling controls Ago2 sorting into exosomes. Cell Rep. 2016;15 (5):978-987. doi:10.1016/j.celrep.2016.03.085

215. Wei JX, Lv LH, Wan YL, et al. Vps4A functions as a tumor suppressor by regulating the secretion and uptake of exosomal microRNAs in human hepatoma cells. Hepatology. 2015;61 (4):1284-1294. doi:10.1002/hep.27660

216. Villarroya-Beltri C, Gutiérrez-Vázquez C, Sánchez-Cabo F, et al. Sumoylated hnRNPA2B1 controls the sorting of miRNAs into exosomes through binding to specific motifs. Nat Commun. 2013;4:2980. doi:10.1038/ncomms3980

217. Lee H, Li C, Zhang Y, Zhang D, Otterbein LE, Jin Y. Caveolin-1 selectively regulates microRNA sorting into microvesicles after noxious stimuli. $J$ Exp Med. 2019;216(9):2202-2220. doi:10.1084/jem.20182313

218. Santangelo L, Giurato G, Cicchini C, et al. The RNA-binding protein SYNCRIP is a component of the hepatocyte exosomal machinery controlling microRNA sorting. Cell Rep. 2016;17 (3):799-808. doi:10.1016/j.celrep.2016.09.031

219. Hagiwara K, Katsuda T, Gailhouste L, Kosaka N, Ochiya T. Commitment of Annexin A2 in recruitment of microRNAs into extracellular vesicles. FEBS Lett. 2015;589(24Pt B):4071-4078. doi:10.1016/j.febslet.2015.11.036

220. Liang J, Zhang X, He S, et al. Sphk2 RNAi nanoparticles suppress tumor growth via downregulating cancer cell derived exosomal microRNA. J Control Release. 2018;286:348-357. doi:10.1016/j.jconrel.2018.07.039

221. Mukherjee K, Ghoshal B, Ghosh S, et al. Reversible HuR-microRNA binding controls extracellular export of miR-122 and augments stress response. EMBO Rep. 2016;17 (8):1184-1203. doi:10.15252/embr.201541930

222. Kosaka N, Iguchi H, Ochiya T. Circulating microRNA in body fluid: a new potential biomarker for cancer diagnosis and prognosis. Cancer Sci. 2010;101(10):2087-2092. doi:10.1111/ j.1349-7006.2010.01650.x

223. Lu P, Li H, Li N, et al. MEX3C interacts with adaptor-related protein complex 2 and involves in miR-451a exosomal sorting. PLoS One. 2017;12(10):e185992. doi:10.1371/journal. pone. 0185992

224. Bolukbasi MF, Mizrak A, Ozdener GB, et al. miR-1289 and "Zipcode"-like sequence enrich mRNAs in microvesicles. Mol Ther Nucleic Acids. 2012;1(2):e10. doi:10.1038/mtna.2011.2 
225. Wei Z, Batagov AO, Schinelli S, et al. Coding and noncoding landscape of extracellular RNA released by human glioma stem cells. Nat Commun. 2017;8(1):1145. doi:10.1038/s41467-01701196-x

226. Russell AE, Sneider A, Witwer KW, et al. Biological membranes in EV biogenesis, stability, uptake, and cargo transfer: an ISEV position paper arising from the ISEV membranes and EVs workshop. J Extracell Vesicles. 2019;8(1):1684862. doi:10.1080/ 20013078.2019.1684862

227. Prattichizzo F, Matacchione G, Giuliani A, et al. Extracellular vesicle-shuttled miRNAs: a critical appraisal of their potential as nano-diagnostics and nano-therapeutics in type 2 diabetes mellitus and its cardiovascular complications. Theranostics. 2021;11 (3):1031-1045. doi:10.7150/thno.51605

228. Zuccato E, Blott EJ, Holt O, et al. Sorting of Fas ligand to secretory lysosomes is regulated by mono-ubiquitylation and phosphorylation. $J$ Cell Sci. 2007;120(Pt 1):191-199. doi: $10.1242 /$ jcs. 03315

229. Saman S, Kim W, Raya M, et al. Exosome-associated tau is secreted in tauopathy models and is selectively phosphorylated in cerebrospinal fluid in early Alzheimer disease. J Biol Chem. 2012;287(6):3842-3849. doi:10.1074/jbc.M111.277061

230. Valapala M, Thamake SI, Vishwanatha JK. A competitive hexapeptide inhibitor of annexin A2 prevents hypoxia-induced angiogenic events. J Cell Sci. 2011;124(Pt9):1453-1464. doi:10.1242/ jes. 079236

231. Delacour D, Greb C, Koch A, et al. Apical sorting by galectin-3-dependent glycoprotein clustering. Traffic. 2007;8 (4):379-388. doi:10.1111/j.1600-0854.2007.00539.x

232. Delacour D, Cramm-Behrens CI, Drobecq H, Le Bivic A, Naim HY, Jacob R. Requirement for galectin-3 in apical protein sorting. Curr Biol. 2006;16(4):408-414. doi:10.1016/j. cub.2005.12.046

233. Cloutier N, Tan S, Boudreau LH, et al. The exposure of autoantigens by microparticles underlies the formation of potent inflammatory components: the microparticle-associated immune complexes. EMBO Mol Med. 2013;5(2):235-249. doi:10.1002/ emmm. 201201846

234. Skriner K, Adolph K, Jungblut PR, Burmester GR. Association of citrullinated proteins with synovial exosomes. Arthritis Rheum. 2006;54(12):3809-3814. doi:10.1002/art.22276

235. Shen B, Wu N, Yang JM, Gould SJ. Protein targeting to exosomes/microvesicles by plasma membrane anchors. J Biol Chem. 2011;286(16):14383-14395. doi:10.1074/jbc.M110.208660

236. Surgucheva I, Sharov VS, Surguchov A. $\gamma$-Synuclein: seeding of $\alpha$-synuclein aggregation and transmission between cells. Biochemistry. 2012;51(23):4743-4754. doi:10.1021/bi300478w

237. Sterzenbach U, Putz U, Low LH, Silke J, Tan SS, Howitt J. Engineered exosomes as vehicles for biologically active proteins. Mol Ther. 2017;25(6):1269-1278. doi:10.1016/j. ymthe.2017.03.030

238. Mathivanan S, Lim JW, Tauro BJ, Ji H, Moritz RL, Simpson RJ. Proteomics analysis of A33 immunoaffinity-purified exosomes released from the human colon tumor cell line LIM1215 reveals a tissue-specific protein signature. Mol Cell Proteomics. 2010;9 (2):197-208. doi:10.1074/mcp.M900152-MCP200

239. Yuana Y, Sturk A, Nieuwland R. Extracellular vesicles in physiological and pathological conditions. Blood Rev. 2013;27 (1):31-39. doi:10.1016/j.blre.2012.12.002

240. Lowry MC, Gallagher WM, O'Driscoll L. The role of exosomes in breast cancer. Clin Chem. 2015;61(12):1457-1465. doi:10.1373/clinchem.2015.240028

241. Im EJ, Lee CH, Moon PG, et al. Sulfisoxazole inhibits the secretion of small extracellular vesicles by targeting the endothelin receptor A. Nat Commun. 2019;10(1):1387. doi:10.1038/s41467019-09387-4
242. Catalano M, O'Driscoll L. Inhibiting extracellular vesicles formation and release: a review of EV inhibitors. $J$ Extracell Vesicles. 2020;9(1):1703244. doi:10.1080/20013078. 2019.1703244

243. Kosaka N, Iguchi H, Yoshioka Y, Takeshita F, Matsuki Y, Ochiya T. Secretory mechanisms and intercellular transfer of microRNAs in living cells. $J$ Biol Chem. 2010;285 (23):17442-17452. doi:10.1074/jbc.M110.107821

244. Wei Y, Li M, Cui S, et al. Shikonin inhibits the proliferation of human breast cancer cells by reducing tumor-derived exosomes. Molecules. 2016;21(6). doi:10.3390/molecules21060777

245. Burnley-Hall N, Willis G, Davis J, Rees DA, James PE. Nitritederived nitric oxide reduces hypoxia-inducible factor $1 \alpha$-mediated extracellular vesicle production by endothelial cells. Nitric Oxide. 2017;63:1-12. doi:10.1016/j.niox.2016.12.005

246. Overmiller AM, Pierluissi JA, Wermuth PJ, et al. Desmoglein 2 modulates extracellular vesicle release from squamous cell carcinoma keratinocytes. FASEB J. 2017;31(8):3412-3424. doi:10.1096/fj.201601138RR

247. Kosgodage US, Trindade RP, Thompson PR, Inal JM, Lange S. Chloramidine/Bisindolylmaleimide-I-mediated inhibition of exosome and microvesicle release and enhanced efficacy of cancer chemotherapy. Int $J$ Mol Sci. 2017;18(5). doi:10.3390/ ijms 18051007

248. Fogli S, Neri T, Nuti E, Mattii L, Camodeca C, Rossello A. Matrix metalloproteinase inhibitors prevent the release and proteolytic activity of monocyte/macrophage-derived microparticles. Pharmacol Rep. 2019;71(3):485-490. doi:10.1016/j. pharep.2019.01.013

249. Koumangoye RB, Sakwe AM, Goodwin JS, Patel T, Ochieng J. Detachment of breast tumor cells induces rapid secretion of exosomes which subsequently mediate cellular adhesion and spreading. PLoS One. 2011;6(9):e24234. doi:10.1371/journal. pone. 0024234

250. Emam SE, Ando H, Abu Lila AS, et al. A Novel strategy to increase the yield of exosomes (extracellular vesicles) for an expansion of basic research. Biol Pharm Bull. 2018;41 (5):733-742. doi:10.1248/bpb.b17-00919

251. King HW, Michael MZ, Gleadle JM. Hypoxic enhancement of exosome release by breast cancer cells. BMC Cancer. 2012;12:421. doi:10.1186/1471-2407-12-421

252. Hannafon BN, Carpenter KJ, Berry WL, Janknecht R, Dooley WC, Ding WQ. Exosome-mediated microRNA signaling from breast cancer cells is altered by the anti-angiogenesis agent docosahexaenoic acid (DHA). Mol Cancer. 2015;14:133. doi:10.1186/s12943-015-0400-7

253. Chao OS, Chang TC, Di Bella MA, et al. The HDAC6 Inhibitor Tubacin induces release of $\mathrm{CD} 133(+)$ extracellular vesicles from cancer cells. J Cell Biochem. 2017;118(12):4414-4424. doi:10.1002/jcb.26095

254. Zhang C, Xiao X, Chen M, Aldharee H, Chen Y, Long W. Liver kinase B1 restoration promotes exosome secretion and motility of lung cancer cells. Oncol Rep. 2018;39(1):376-382. doi:10.3892/ or.2017.6085

255. Nkosi D, Sun L, Duke LC, et al. Epstein-Barr virus LMP1 promotes Syntenin-1- and Hrs-induced extracellular vesicle formation for its own secretion to increase cell proliferation and migration. mBio. 2020;11(3). doi:10.1128/mBio.00589-20

256. Fan SJ, Kroeger B, Marie PP, et al. Glutamine deprivation alters the origin and function of cancer cell exosomes. EMBOj. 2020;39 (16):e103009. doi:10.15252/embj.2019103009

257. Montermini L, Meehan B, Garnier D, et al. Inhibition of oncogenic epidermal growth factor receptor kinase triggers release of exosome-like extracellular vesicles and impacts their phosphoprotein and DNA content. J Biol Chem. 2015;290(40):24534-24546. doi:10.1074/jbc.M115.679217 
258. Fujiwara T, Eguchi T, Sogawa C, et al. Anti-EGFR antibody cetuximab is secreted by oral squamous cell carcinoma and alters EGF-driven mesenchymal transition. Biochem Biophys Res Commun. 2018;503(3):1267-1272. doi:10.1016/j. bbrc.2018.07.035

259. Clayton A, Turkes A, Navabi H, Mason MD, Tabi Z. Induction of heat shock proteins in B-cell exosomes. J Cell Sci. 2005;118(Pt 16):3631-3638. doi: $10.1242 /$ jcs. 02494

260. Lancaster GI, Febbraio MA. Exosome-dependent trafficking of HSP70: a novel secretory pathway for cellular stress proteins. $J$ Biol Chem. 2005;280(24):23349-23355. doi:10.1074/jbc. M502017200

261. Taha EA, Ono K, Eguchi T. Roles of extracellular HSPs as biomarkers in immune surveillance and immune evasion. Int J Mol Sci. 2019;20(18). doi:10.3390/ijms20184588

262. Atienzar-Aroca S, Flores-Bellver M, Serrano-Heras G, et al. Oxidative stress in retinal pigment epithelium cells increases exosome secretion and promotes angiogenesis in endothelial cells. J Cell Mol Med. 2016;20(8):1457-1466. doi:10.1111/ jcmm. 12834

263. Bewicke-Copley F, Mulcahy LA, Jacobs LA, et al. Extracellular vesicles released following heat stress induce bystander effect in unstressed populations. $J$ Extracell Vesicles. 2017;6(1):1340746. doi:10.1080/20013078.2017.1340746

264. Hedlund M, Nagaeva O, Kargl D, Baranov V, Mincheva-Nilsson L. Thermal- and oxidative stress causes enhanced release of NKG2D ligand-bearing immunosuppressive exosomes in leukemia/lymphoma T and B cells. PLoS One. 2011;6(2):e16899. doi:10.1371/journal.pone.0016899

265. Collett GP, Redman CW, Sargent IL, Vatish M. Endoplasmic reticulum stress stimulates the release of extracellular vesicles carrying danger-associated molecular pattern (DAMP) molecules. Oncotarget. 2018;9(6):6707-6717. doi:10.18632/ oncotarget. 24158

266. Sudnitsyna J, Skverchinskaya E, Dobrylko I, Nikitina E, Gambaryan S, Mindukshev I. Microvesicle formation induced by oxidative stress in human erythrocytes. Antioxidants (Basel). 2020;9(10). doi:10.3390/antiox9100929

267. Harmati M, Gyukity-Sebestyen E, Dobra G, et al. Small extracellular vesicles convey the stress-induced adaptive responses of melanoma cells. Sci Rep. 2019;9(1):15329. doi:10.1038/s41598019-51778-6

268. Zhu L, Zang J, Liu B, et al. Oxidative stress-induced RAC autophagy can improve the HUVEC functions by releasing exosomes. $J$ Cell Physiol. 2020;235(10):7392-7409. doi: $10.1002 /$ jcp. 29641

269. Gurunathan S, Kang MH, Jeyaraj M, Kim JH. Platinum nanoparticles enhance exosome release in human lung epithelial adenocarcinoma cancer cells (A549): oxidative stress and the ceramide pathway are key players. Int J Nanomedicine. 2021;16:515-538. doi:10.2147/ijn.S291138

270. Luan X, Sansanaphongpricha K, Myers I, Chen H, Yuan H, Sun D. Engineering exosomes as refined biological nanoplatforms for drug delivery. Acta Pharmacol Sin. 2017;38(6):754-763. doi:10.1038/aps.2017.12

271. Sun D, Zhuang X, Xiang X, et al. A novel nanoparticle drug delivery system: the anti-inflammatory activity of curcumin is enhanced when encapsulated in exosomes. Mol Ther. 2010;18 (9):1606-1614. doi:10.1038/mt.2010.105

272. Tian Y, Li S, Song J, et al. A doxorubicin delivery platform using engineered natural membrane vesicle exosomes for targeted tumor therapy. Biomaterials. 2014;35(7):2383-2390. doi:10.1016/j.biomaterials.2013.11.083

273. Wang J, Zheng Y, Zhao M. Exosome-based cancer therapy: implication for targeting cancer stem cells. Front Pharmacol. 2016;7:533. doi:10.3389/fphar.2016.00533
274. Wang J, Dong Y, Li Y, et al. Designer exosomes for active targeted chemo-photothermal synergistic tumor therapy. $A d v$ Funct Mater. 2018;28(18):1707360. doi:10.1002/adfm. 201707360

275. Hong Y, Nam G-H, Koh E, et al. Exosome as a vehicle for delivery of membrane protein therapeutics, $\mathrm{PH} 20$, for enhanced tumor penetration and antitumor efficacy. Adv Funct Mater. 2018;28(5):1703074. doi:10.1002/adfm.201703074

276. Alvarez-Erviti L, Seow Y, Yin H, Betts C, Lakhal S, Wood MJ. Delivery of siRNA to the mouse brain by systemic injection of targeted exosomes. Nat Biotechnol. 2011;29(4):341-345. doi:10.1038/nbt.1807

277. El-Andaloussi S, Lee Y, Lakhal-Littleton S, et al. Exosomemediated delivery of siRNA in vitro and in vivo. Nat Protoc. 2012;7(12):2112-2126. doi:10.1038/nprot.2012.131

278. Bellavia D, Raimondo S, Calabrese G, et al. Interleukin 3- receptor targeted exosomes inhibit in vitro and in vivo chronic myelogenous leukemia cell growth. Theranostics. 2017;7 (5):1333-1345. doi:10.7150/thno.17092

279. Kojima R, Bojar D, Rizzi G, et al. Designer exosomes produced by implanted cells intracerebrally deliver therapeutic cargo for Parkinson's disease treatment. Nat Commun. 2018;9(1):1305. doi:10.1038/s41467-018-03733-8

280. György B, Sage C, Indzhykulian AA, et al. Rescue of hearing by gene delivery to inner-ear hair cells using exosome-associated AAV. Mol Ther. 2017;25(2):379-391. doi:10.1016/j. ymthe.2016.12.010

281. Barbosa FMC, Dupin TV, Toledo MDS, et al. Extracellular vesicles released by Leishmania (Leishmania) amazonensis promote disease progression and induce the production of different cytokines in macrophages and B-1 Cells. Front Microbiol. 2018;9:3056. doi:10.3389/fmicb.2018.03056

282. Roig J, Saiz ML, Galiano A, et al. Extracellular vesicles from the helminth fasciola hepatica prevent DSS-induced acute ulcerative colitis in a T-lymphocyte independent mode. Front Microbiol. 2018;9:1036. doi:10.3389/fmicb.2018.01036

283. Eichenberger RM, Talukder MH, Field MA, et al. Characterization of Trichuris muris secreted proteins and extracellular vesicles provides new insights into host-parasite communication. $J$ Extracell Vesicles. 2018;7(1):1428004. doi:10.1080/20013078.2018.1428004

284. Yuan D, Zhao Y, Banks WA, et al. Macrophage exosomes as natural nanocarriers for protein delivery to inflamed brain. Biomaterials. 2017;142:1-12. doi:10.1016/j.biomaterials. 2017.07.011

285. Haney MJ, Klyachko NL, Zhao Y, et al. Exosomes as drug delivery vehicles for Parkinson's disease therapy. J Control Release. 2015;207:18-30. doi:10.1016/j.jconrel.2015.03.033

286. Yim N, Ryu SW, Choi K, et al. Exosome engineering for efficient intracellular delivery of soluble proteins using optically reversible protein-protein interaction module. Nat Commun. 2016;7:12277. doi:10.1038/ncomms 12277

287. Wolfers J, Lozier A, Raposo G, et al. Tumor-derived exosomes are a source of shared tumor rejection antigens for CTL cross-priming. Nat Med. 2001;7(3):297-303. doi:10.1038/85438

288. Ouyang W, O'Garra A. IL-10 family cytokines IL-10 and IL-22: from basic science to clinical translation. Immunity. 2019;50 (4):871-891. doi:10.1016/j.immuni.2019.03.020

289. Tang TT, Wang $\mathrm{B}$, $\mathrm{Wu} \mathrm{M}$, et al. Extracellular vesicle-encapsulated IL-10 as novel nanotherapeutics against ischemic AKI. Sci Adv. 2020;6(33):eaaz0748. doi:10.1126/ sciadv.aaz0748

290. Bruno S, Grange C, Collino F, et al. Microvesicles derived from mesenchymal stem cells enhance survival in a lethal model of acute kidney injury. PLoS One. 2012;7(3):e33115. doi:10.1371/ journal.pone.0033115 
291. Lai RC, Arslan F, Lee MM, et al. Exosome secreted by MSC reduces myocardial ischemia/reperfusion injury. Stem Cell Res. 2010;4(3):214-222. doi:10.1016/j.scr.2009.12.003

292. Tan X, Gong YZ, Wu P, Liao DF, Zheng XL. Mesenchymal stem cell-derived microparticles: a promising therapeutic strategy. Int $J$ Mol Sci. 2014;15(8):14348-14363. doi:10.3390/ ijms150814348

293. Yan Y, Jiang W, Tan Y, et al. hucMSC exosome-derived GPX1 is required for the recovery of hepatic oxidant injury. Mol Ther. 2017;25(2):465-479. doi:10.1016/j.ymthe.2016.11.019

294. Mardpour S, Ghanian MH, Sadeghi-Abandansari H, et al. Hydrogel-mediated sustained systemic delivery of mesenchymal stem cell-derived extracellular vesicles improves hepatic regeneration in chronic liver failure. ACS Appl Mater Interfaces. 2019;11(41):37421-37433. doi:10.1021/acsami.9b10126

295. Zhang Y, Jin X, Liang J, et al. Extracellular vesicles derived from ODN-stimulated macrophages transfer and activate $\mathrm{Cdc} 42$ in recipient cells and thereby increase cellular permissiveness to EV uptake. Sci Adv. 2019;5(7):eaav1564. doi:10.1126/sciadv. aav1564

296. Usman WM, Pham TC, Kwok YY, et al. Efficient RNA drug delivery using red blood cell extracellular vesicles. Nat Commun. 2018;9(1):2359. doi:10.1038/s41467-018-04791-8

297. Skog J, Würdinger T, van Rijn S, et al. Glioblastoma microvesicles transport RNA and proteins that promote tumour growth and provide diagnostic biomarkers. Nat Cell Biol. 2008;10 (12):1470-1476. doi:10.1038/ncb1800

298. Shao H, Chung J, Lee K, et al. Chip-based analysis of exosomal mRNA mediating drug resistance in glioblastoma. Nat Commun. 2015;6:6999. doi:10.1038/ncomms7999

299. Melo SA, Luecke LB, Kahlert C, et al. Glypican-1 identifies cancer exosomes and detects early pancreatic cancer. Nature. 2015;523(7559):177-182. doi:10.1038/nature14581
300. Park J, Lin HY, Assaker JP, et al. Integrated kidney exosome analysis for the detection of kidney transplant rejection. ACS Nano. 2017;11(11):11041-11046. doi:10.1021/acsnano.7b05083

301. Meng W, He C, Hao Y, Wang L, Li L, Zhu G. Prospects and challenges of extracellular vesicle-based drug delivery system: considering cell source. Drug Deliv. 2020;27(1):585-598. doi:10.1080/10717544.2020.1748758

302. Rufino-Ramos D, Albuquerque PR, Carmona V, Perfeito R, Nobre RJ, Pereira de Almeida L. Extracellular vesicles: novel promising delivery systems for therapy of brain diseases. $J$ Control Release. 2017;262:247-258. doi:10.1016/j. jconrel.2017.07.001

303. Das CK, Jena BC, Banerjee I, et al. Exosome as a novel shuttle for delivery of therapeutics across biological barriers. Mol Pharm. 2019;16(1):24-40. doi:10.1021/acs.molpharmaceut.8b00901

304. Zhang K, Zhao X, Chen X, et al. Enhanced therapeutic effects of mesenchymal stem cell-derived exosomes with an injectable hydrogel for hindlimb ischemia treatment. ACS Appl Mater Interfaces. 2018;10(36):30081-30091. doi:10.1021/acsami.8b08449

305. Tian T, Zhang HX, He CP, et al. Surface functionalized exosomes as targeted drug delivery vehicles for cerebral ischemia therapy. Biomaterials. 2018;150:137-149. doi:10.1016/j.biomaterials. 2017.10.012

306. Yamashita T, Takahashi Y, Takakura Y. Possibility of exosome-based therapeutics and challenges in production of exosomes eligible for therapeutic application. Biol Pharm Bull. 2018;41(6):835-842. doi:10.1248/bpb.b18-00133

307. Rosell A, Havervall S, von Meijenfeldt F, et al. Patients with COVID-19 have elevated levels of circulating extracellular vesicle tissue factor activity that is associated with severity and mortality. Arterioscler Thromb Vasc Biol. 2020;41(2): Atvbaha120315547. doi:10.1161/atvbaha.120.315547
International Journal of Nanomedicine

\section{Publish your work in this journal}

The International Journal of Nanomedicine is an international, peerreviewed journal focusing on the application of nanotechnology in diagnostics, therapeutics, and drug delivery systems throughout the biomedical field. This journal is indexed on PubMed Central, MedLine, CAS, SciSearch ${ }^{\mathbb{R}}$, Current Contents ${ }^{\mathbb{B}} /$ Clinical Medicine,
Journal Citation Reports/Science Edition, EMBase, Scopus and the Elsevier Bibliographic databases. The manuscript management system is completely online and includes a very quick and fair peer-review system, which is all easy to use. Visit http://www.dovepress.com/ testimonials.php to read real quotes from published authors. 